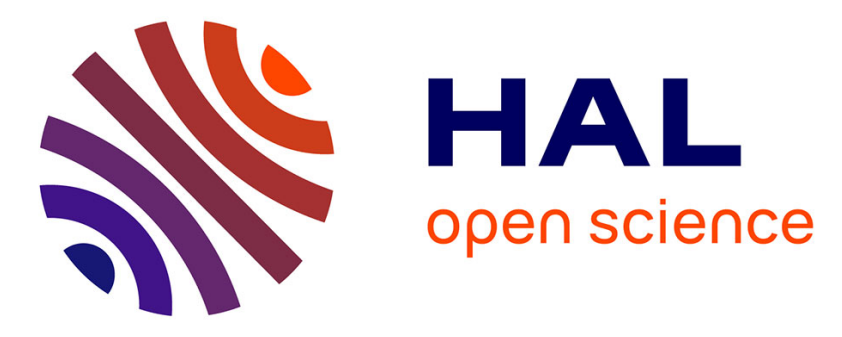

\title{
Trace elemental partitioning in hydrothermal muds from the El Tatio Geyser Field, Chile
}

\author{
Weiduo Hao, Kaarel Mänd, Logan Swaren, Kimberly D Myers, Stefan \\ Lalonde, Dylan T Wilmeth, Mark van Zuilen, Siobhan A Wilson, Daniel S \\ Alessi, Kurt O Konhauser
}

\section{To cite this version:}

Weiduo Hao, Kaarel Mänd, Logan Swaren, Kimberly D Myers, Stefan Lalonde, et al.. Trace elemental partitioning in hydrothermal muds from the El Tatio Geyser Field, Chile. Journal of Geophysical Research : Solid Earth, 2021, 126 (5), pp.e2020JB021422. 10.1029/2020JB021422 . hal-03456841

\section{HAL Id: hal-03456841 \\ https://hal.science/hal-03456841}

Submitted on 30 Nov 2021

HAL is a multi-disciplinary open access archive for the deposit and dissemination of scientific research documents, whether they are published or not. The documents may come from teaching and research institutions in France or abroad, or from public or private research centers.
L'archive ouverte pluridisciplinaire HAL, est destinée au dépôt et à la diffusion de documents scientifiques de niveau recherche, publiés ou non, émanant des établissements d'enseignement et de recherche français ou étrangers, des laboratoires publics ou privés. 


\section{Trace elemental partitioning in hydrothermal muds from the El Tatio Geyser Field, Chile}

Weiduo Haa ${ }^{\mathrm{a} *}$, Kaarel Mänd ${ }^{\mathrm{a}, \mathrm{b}}$, Logan Swaren ${ }^{\mathrm{a}}$, Kimberly D. Myers ${ }^{\mathrm{c}}$, Stefan Lalonde ${ }^{\mathrm{d}}$, Dylan T. Wilmeth $^{\mathrm{c}}$, Mark Van Zuilen ${ }^{\mathrm{c}}$, Siobhan A. Wilson ${ }^{\mathrm{a}}$, Daniel S. Alessi ${ }^{\mathrm{a}}$, Kurt O. Konhauser ${ }^{\mathrm{a}}$

${ }^{a}$ Department of Earth \& Atmospheric Sciences, University of Alberta, Edmonton, Alberta, T6G 2E3, Canada.

${ }^{\mathrm{b}}$ Department of Geology, University of Tartu, Ravila 14A, Tartu 50411, Estonia.

${ }^{c}$ Université de Paris, Institut de physique du globe de Paris, CNRS, F-75005 Paris, France.

dLaboratoire Géosciences Océan, Institut Universitaire Européen de la Mer, 29280 Plouzané,

France

*Corresponding author:

Weiduo Hao

3-11 Earth Sciences Building, University of Alberta, Edmonton, AB T6G 2E3, Canada

$+1(587)-990-2819$

whao@ualberta.ca 


\section{Abstract:}

Clay minerals are ubiquitous in surface environments and are important vectors in the transport of trace elements from land to the oceans. Recent laboratory experimental studies have demonstrated that clay minerals bind more trace elements under aqueous conditions associated with acidic chemical weathering than in estuarine or marine depositional environments, indicating that clays serve as a source of some trace metals to seawater. In order to determine if clays behave similarly under natural conditions, we collected water and mud samples from 5 boiling, low-pH mud pools venting at the El Tatio Geyser Field (ETGF) in Chile. X-ray diffraction (XRD) and scanning electron microscopy (SEM) analyses showed that 38.5-61.1\% of the mud samples are composed of clay minerals, such as kaolinite and montmorillonite, with lesser amounts of feldspar (sanidine), muscovite, silica (quartz and cristobalite), and possibly amorphous Fe-S-As and As-Sb phases that are unidentified by XRD. Proton-active functional group densities varied between 0.16 and $0.2 \mathrm{mmol} / \mathrm{g}$, as determined by acid-base titrations. Based on elemental abundances in the aqueous and solid phases at the mud pools under ambient conditions ( $\mathrm{pH}$ values and temperatures ranged from $2.5-5.8$ and $40-80^{\circ} \mathrm{C}$, respectively), we determined concentration factors (in log scale) between 0.5 to 2 for $\mathrm{Na}$ and $\mathrm{Li}$, and 2 to 5 for $\mathrm{Ce}$, $\mathrm{Al}, \mathrm{U}, \mathrm{Fe}, \mathrm{Ba}, \mathrm{Zn}, \mathrm{Mg}, \mathrm{Si}, \mathrm{Co}, \mathrm{Cr}, \mathrm{As}, \mathrm{Pb}$, and $\mathrm{P}$. We also observed that mud samples collected from lower $\mathrm{pH}$ ponds (e.g., $\mathrm{pH}=2.42,3.55$ ) have high concentration factors for anions (such as $\mathrm{P}$ and As) but low concentration factors for cations (such as $\mathrm{Ca}, \mathrm{Mn}$ and $\mathrm{Sr}$ ), while mud samples collected from higher $\mathrm{pH}$ ponds (e.g., $\mathrm{pH}=4.87,5.84$ ) display the opposite trend. Acid-base leaching experiments demonstrated that increasing solution $\mathrm{pH}$ (to reflect downstream transport) releases As, Mo and P from the clay mineral surfaces; decreasing $\mathrm{pH}$ (to determine the effects of re-acidification) releases $\mathrm{Li}, \mathrm{Na}, \mathrm{Ca}, \mathrm{Co}, \mathrm{Sr}, \mathrm{Mo}$ and $\mathrm{Cd}$. All remaining elements were effectively 
immobile during acid-base leaching experiments. Our study shows: (1) that clay minerals in natural environments can assemble a diverse inventory of trace elements; and (2) during transport away from acid weathering sites, some of those elements (e.g., As) can be desorbed back into the aqueous phase. Previous investigations on regional As contamination in the ETGF have focused on the high As fraction associated with iron oxide surfaces, draining from the El Tatio headwaters to the Rio Salado and Rio Loa. Our findings show that metal/metalloid desorption from clays during downstream transport likely also contributes to As contamination in the Río Loa, the primary source of drinking and agricultural water in Region II, Chile.

\section{Introduction}

Clays are amongst the most abundant minerals at the Earth's surface and their impact on global trace element cycling stems from their ability to accumulate a range of trace elements, with the magnitude of adsorption being directly tied to their high surface charge and surface area (Sposito et al., 1999; Tournassat et al., 2004; Landry et al., 2009; Tournassat et al., 2016). Previous studies have shown that clay mineral surface charge varies with the ionic strength and $\mathrm{pH}$ of the background electrolyte solution (Sverjensky and Sahai, 1996; Sahai and Sverjensky, 1997; Bradbury and Baeyens, 2002; Gu and Evans, 2007; Bradbury and Baeyens, 2009; Liu et al., 2018; Hao et al., 2019a). Accordingly, as clay-bearing particles are transported from land to the oceans, the change in aqueous conditions from freshwater and slightly acidic $(\mathrm{pH}=6$, ionic strength $=0.01$ M) to saline and alkaline ( $\mathrm{pH}=8$, ionic strength=0.56 $\mathrm{M}-0.7 \mathrm{M})$ influences clay mineral surface properties, and ultimately affects the speciation and degree of adsorption of trace metals on clay mineral surfaces. For instance, previous studies demonstrated that an increase in solution ionic strength can attenuate the net negative electrostatic field at the clay surface, decreasing cation 
adsorption and increasing anion adsorption (Hao et al., 2018; Hao et al., 2019a; Hao et al., 2020). Conversely, the increase in $\mathrm{pH}$ from freshwater to marine conditions promotes the deprotonation of clay surface functional groups, generating additional negative charge which facilitates cation adsorption but inhibits anion adsorption.

Clay minerals that have experienced acid exposure (e.g., during acid rock drainage) have higher surface areas than clays generated in the presence of circumneutral aqueous solutions, and thus display different surface properties and element affinities. For instance, Hao et al. (2019b) showed significant increases in the surface areas of clay minerals (kaolinite, illite, and montmorillonite) after exposure to acidic solutions ( $\mathrm{pH} \sim 0-4)$, as well as decreased cadmium $(\mathrm{Cd})$ adsorption. Similarly, Jeon and Nam (2019) showed that acidic treatment can decrease the surface functional group density and the proton binding constants of montmorillonite. Other variations in aqueous conditions can also change the affinity of trace elements to clays. For example, Hao et al. (2020) measured decreased Cd adsorption to illite and montmorillonite in solutions with increasing $\mathrm{pH}(6-8)$ and ionic strength $(0.01-0.56 \mathrm{M})$, mimicking changes from freshwater to seawater aqueous conditions. Those authors subsequently hypothesized that metal desorption in marginal marine settings could liberate trace metals to seawater, impacting primary productivity.

The next step in assessing the Hao et al. (2020) hypothesis is to study the association of trace elements with clay minerals in naturally acidic environments. In this regard, terrestrial hydrothermal settings are suitable because vent effluents are commonly acidic and rich in an assortment of trace metals, while the acidic steam actively promotes the in-situ formation of clay minerals. Previous field studies conducted by Liu et al. (2009) and Alsina et al. (2014) explored arsenic (As) geochemistry in geyser fields of China and Chile, respectively, and showed that the 
majority of aqueous As is adsorbed onto solid particles, as opposed to being present as free ions; and that particle-bound As is a significant source of groundwater As. Morteani et al. (2014) studied trace element concentrations in water and mud at hot springs in the Cordillera and the Altiplano of Bolivia. While these studies emphasize the occurrence of specific trace elements in the mud samples on a local scale, the surface reactivity and chemical speciation of surface functional groups of minerals within mud samples remains poorly understood, especially during environmental $\mathrm{pH}$ variations. Clay minerals experience a variety of chemical conditions during downstream transport; therefore, developing a flexible model that predicts the reactivity of clay minerals towards metals with varying environmental conditions is critical to accurately determining metal speciation, adsorption and transport.

Our study focused on the El Tatio Geyser Field (ETGF), which is located in the northern part of the Atacama Desert in Chile (Figure 1) at a local elevation of $~ 4300 \mathrm{~m}$ above sea level. The geyser fluids contain high concentrations of geogenic trace elements (e.g., As and antimony, $\mathrm{Sb}$ ), and contribute to high levels of these elements in the Rio Loa, one of the main water sources for agriculture and human consumption in the Antofagasta region of Northern Chile (Landrum et al., 2009; Leiva et al., 2014). Runoff from the ETGF and other As-rich geothermal fields and mining sites combine to make As pollution a major issue for water utilization and a human health risk factor in Northern Chile (Smith et al., 2012; Leiva et al., 2014). Studies at ETGF have included: (1) fluid characterization and gas composition to trace the source of the fluids (Tassi et al., 2009; Tassi et al., 2010), (2) environmental partitioning and phase associations of As and Sb along El Tatio geyser outflows (Landrum et al., 2009) and in the regional watershed draining from ETGF (Alsina et al., 2014), (3) sedimentary fingerprints of microbial activity (FernandezTuriel et al., 2005; Sanchez-Garcia et al., 2019; Gong et al., 2019; Wilmeth et al., 2020; Gong et 
al., 2020), and (4) hydraulic and physico-chemical properties (Nicolau et al., 2014; Munoz-Saez et al., 2016; Munoz-Saez et al., 2018).

In this study, we sampled different boiling mud pots in the ETGF to study the partitioning and distribution of trace elements in hot spring muds and their speciation on clay mineral surface functional groups. Our goals are to (1) characterize the muds that naturally exist in the ETGF, (2) assess their control on trace element behaviour, (3) determine the amount of trace elements that are weakly bound to clay mineral surfaces, and (4) predict the potential for trace element release when the muds encounter circumneutral $\mathrm{pH}$ waters and thus how muds affect water quality when transported downstream from the ETGF. Finally, we compare the experimental results with published geochemical data from the Rio Salado and Rio Loa in order to determine the potential contribution of clay-bound transport to metal/metalloid toxicity in northern Chile.

\section{Geological background}

The ETGF is one of the largest and highest elevation $(4300 \mathrm{~m})$ geothermal fields on Earth. The field area comprises an extremely arid plateau - the Northern Chilean Altiplano - extending from the Andes Mountains to the Pacific Ocean. The ETGF is one of several active geothermal fields in northern Chile (Tassi et al., 2010); it is geologically associated with the Altiplano-Puna Volcanic Complex (APVC), a large volcanic zone that extends north and south of the ETGF (Lahsen and Trujillo, 1976; De Silva, 1989; De Silva and Francis, 1991; De Silva et al., 1994).

The ETGF is the largest geyser field in the Southern Hemisphere, and the third largest geyser field in the world, with over 80 active geysers, 30 perpetual spouters, as well as mudpots, warm springs, solfataras, and fumaroles (Glennon and Pfaff, 2003). ETGF water originates as rainwater and snowmelt in the Bolivian Andes $15-20 \mathrm{~km}$ to the east-southeast, moves west 
through the deep subsurface and is heated up to $224^{\circ} \mathrm{C}$ by the Pastos Grandes and Cerro Gaucha caldera systems of the APVC just east of El Tatio (Healy and Hochstein, 1973; Cusicanqui et al., 1976; Lahsen and Trujillo, 1976; Giggenbach, 1978; Magaritz et al., 1990). Upon reaching the ETGF, groundwater becomes confined to two major aquifers: the Puripica and Salado ignimbrites and the Tucle dacite (De Silva, 1989; De Silva et al., 1994). Thermal features are located on north-south-oriented faults of the Tatio graben (Munoz-Saez et al., 2015; 2018).

Most ETGF geothermal features are clustered into areas known as the Upper, Middle, and Lower Geyser basins (Ellis, 1969; Glennon and Pfaff, 2003). The Upper Basin contains the highest number of geothermal features, including geothermal springs with low discharge, and spouting geysers forming well-developed silica sinter terraces along the high vertical relief $\mathrm{N}$ NW margin. The Upper Basin's periphery hosts vegetated slopes with mudpots and fumaroles. The Middle Basin is a flat sinter plain with deep pools and fountain-type eruptions where individual features often have higher discharge than the Upper Basin springs. At higher elevation, the Middle Basin, known as Group M-III, also contains a cluster of active mud pots, springs, and solfateras, forming the main surface runoff that flows through the Middle Basin (Glennon and Pfaff, 2003). The Lower Basin lies along the banks of the Río Salado, the headwaters of which are formed by geyser effluent from all three basins (Supplementary Figure 1).

Two geochemically distinct types of circumneutral $\mathrm{pH}$ and moderately saline fluids emerge from geysers and springs at El Tatio; (i) deeply-sourced, magma-heated water of Na-Cltype, and (ii) meteoric and surface-runoff steam-heated in the shallow subsurface, containing sulfate (Cortecci et al., 2005). The deep, magmatically-derived Na-Cl-type geyser waters are rich in As, B, Cs, and Li (Cortecci et al., 2005), and contain the world's highest naturally occurring 
As and $\mathrm{Sb}$ concentrations found in a surface water $(0.3-0.6 \mathrm{mmol} / \mathrm{L}$ and $10-20 \mu \mathrm{mol} / \mathrm{L}$, respectively, see Landrum et al., 2009), but extremely low DIC (0.1-0.5 mmol C/l, mainly as $\mathrm{HCO}_{3}{ }^{-}$) (Ellis and Mahon, 1964; Ellis and Mahon, 1967; Landrum et al., 2009; Myers, 2015; Plenge et al., 2017). The $\mathrm{pH}$ of geyser waters at ETGF is circumneutral, ranging from 6.8 at most discharge points and increasing to 7.1 as waters cool along outflows (Landrum, 2007; Landrum et al., 2009).

Mud pots, which tend to form along the margins of the hydrothermal field, adjacent to fresh volcanics and vegetation, are sulfate-rich and mostly fed by meteoric water and surface run-off (Cortecci et al., 2005). The contribution of this water into ETGF runoff is smaller than that of the geothermal Na-Cl-type water, but it possesses higher trace metal and dissolved gas concentrations (Tassi et al., 2010; Cortecci et al., 2005; Cardenas and Engel, 2012). In mudpots, locally high $\mathrm{H}_{2} \mathrm{~S}$ gas (oxidizing to sulfuric acid in the aqueous phase), and $\mathrm{CO}_{2}$ from plant roots in sandy, volcanically-derived sediment contribute to high acidity and rapid mineral weathering, resulting in rapid clay formation.

Unlike most natural waters where $\mathrm{pH}$ is buffered by the carbonate system, ETGF waters are strongly buffered by the arsenic acid system at the $\mathrm{pK}_{\mathrm{a} 2}$ of arsenate, $\mathrm{As}(\mathrm{V})\left(\mathrm{H}_{2} \mathrm{AsO}_{4}{ }^{-}\right.$ $+\mathrm{H}_{2} \mathrm{O} \leftrightarrow \mathrm{HAsO}_{4}{ }^{2-}+\mathrm{H}^{+}, \mathrm{pK}_{\mathrm{a} 2}=6.94$, see Landrum et al., 2009). Arsenic also buffers the redox: waters emerge with a 4:1 ratio of $\mathrm{As}(\mathrm{III})$ : $\mathrm{As}(\mathrm{V})$, which is rapidly oxidized in the outflow channels (Landrum et al., 2009; Engel et al., 2013). Although As is a known toxin, microorganisms inhabiting ETGF streams and pools have adapted to tolerate, and in some cases, appear to benefit from the geochemical properties of As, making the ETGF microbial ecosystem unique (Engel et al., 2013; Escudero et al., 2013; Myers, 2015). 
Most springs and geysers discharge water rich in amorphous silica near the local boiling point of $86^{\circ} \mathrm{C}$. Opal-A precipitates as hydrothermal waters cool and evaporate, forming a variety of siliceous sinters at different temperatures and physical environments (Rodgers et al., 2002; Fernandez-Turiel et al., 2005; Phoenix et al., 2006; Garcia-Valles et al., 2008; Landrum et al., 2009; Alsina et al., 2014; Wilmeth et al., 2020). Thin iron oxide coatings are also observed on microbial mats and streamers in the moderate-to-high temperature regions along some geyser outflows (Landrum et al., 2009; Engel et al., 2013).

\section{Methodology}

\subsection{Sample collection}

Five different sites with a range of temperatures, $\mathrm{pH}$ values and mud colors were chosen within an approximately $400 \mathrm{~m}^{2}$ area of the ETGF Upper Basin on the southern edge of the Group UVIII cluster (Figure 1, Table 1). These features were mainly found along the margin of a vegetated, sandy slope, which comprises a range of shallow, steam-heated mud-pots, interspersed with shallow, clear (non-mudpot) spring-fed pools and fumaroles. Solid mud samples were collected from the edges of the mud pots using a scalpel and then immediately placed into $20 \mathrm{~mL}$ high-density polyethylene (HDPE) vials that were filled to the top with mud and sealed. Water samples were collected from the surface of the hot springs using a $20 \mathrm{~mL}$ syringe. The water samples were then filtered through $0.22 \mu \mathrm{m}$ nylon membranes (Agilent Captiva) into the same type of $20 \mathrm{~mL}$ HDPE vials. Three drops of $2 \%$ nitric acid were added to lower the solution $\mathrm{pH}$ to $<3$ in order to prevent metals from either precipitating out of solution or adsorbing to the inner tube surfaces. The $\mathrm{pH}$ and temperature of the sites from which mud samples were collected were measured in situ (see data in Table 1). Once transported to the University of Alberta, the mud 
samples were dried in an oven at $90^{\circ} \mathrm{C}$ overnight to estimate water content.

\subsection{Powder X-ray diffraction analysis (XRD)}

Approximately $500 \mathrm{mg}$ of each oven-dried $\left(40^{\circ} \mathrm{C}\right)$ sample was ground by hand to $<0.4 \mathrm{~mm}$ using an agate mortar and pestle. Each sample was then ground in anhydrous ethanol using agate elements with a McCrone Micronizing Mill for 4 minutes. Samples were air-dried overnight and disaggregated using an agate mortar and pestle. A Ca-exchange was performed in order to

stabilize the basal spacing of smectites to $15 \AA$ following Bish et al. (2003) and using the method described by Mervine et al. (2018). The samples were suspended in $100 \mathrm{~mL}$ of $1 \mathrm{M} \mathrm{CaCl}_{2} \cdot 2 \mathrm{H}_{2} \mathrm{O}$ (Fisher Chemical, Certified ACS grade), sealed in Schott bottles, and agitated vigorously overnight. Following agitation, samples were gravity filtered through filter paper (Whatman no. 1). Samples were then rinsed $3 \times$ with deionized water, dried overnight at room temperature and disaggregated again with an agate mortar and pestle. Because opal was tentatively identified in several samples using scanning electron microscopy (SEM) (see results), 10\% (w/w) of synthetic $\mathrm{CaF}_{2}$ was added to each sample as an internal standard for quantification of this amorphous phase. Following addition of $\mathrm{CaF}_{2}$, each sample was ground for a further 40 seconds under anhydrous ethanol using stainless steel elements in a miniaturized McCrone milling assembly (using the design of Locock et al., 2012).

Diffraction patterns were collected using a Rigaku Ultima IV $\theta-\theta$ powder X-ray diffractometer (XRD) equipped with a $\mathrm{D} / \mathrm{Tex}$ Ultra detector and a cobalt source that was operated at $38 \mathrm{kV}$ and $38 \mathrm{~mA}$. XRD patterns were collected from 5-80 $2 \theta$ using a step size of $0.02^{\circ} 2 \theta$ at a rate of $2^{\circ} 2 \theta /$ minute. Relative humidity was recorded at the beginning and end of each sample pattern collection and a humidifier was run during sample analysis to maintain 
relative humidity in the range of $20-80 \%$ as per Bish et al. (2003). Mineral phase identification was conducted using the DIFFRAC.EVA XRD phase analysis software (Bruker) with reference to the International Center for Diffraction Data Powder Diffraction File 4+ database (ICDD PDF4+). Rietveld refinement (Rietveld, 1969; Hill and Howard, 1987; Bish and Howard, 1988) with XRD data was used to estimate mineral abundances with TOPAS 5 (Bruker). Fundamental parameters peak fitting (Cheary and Coelho, 1992) was used for all phases. The Partial Or No Known Crystal Structure (PONKCS; (Scarlett and Madsen, 2006) method of structureless fitting was used to model the XRD patterns of kaolinite and montmorillonite to account for turbostratic stacking disorder. The use of Rietveld-compatible structureless fitting methods can result in overestimates of the structurally disordered phases for which they are used owing to overestimation of peak intensities at the expense of other phases with overlapping peaks (Wilson et al., 2006; Turvey et al., 2018). As such, when physically implausible peak intensities were observed for kaolinite or montmorillonite (in the late stages of refinement) we accepted refined parameters prior to convergence of the model.

\subsection{Scanning electron microscopy}

Dried, powdered samples were mounted on adhesive carbon films and sputtered with a nm-thick carbon layer to increase conductivity for SEM analyses. The samples were imaged on a Zeiss Sigma $300 \mathrm{VP}-\mathrm{FESEM}$ at an accelerating voltage of $10 \mathrm{kV}$ operating in high-vacuum mode. Signals were collected with secondary electron (SE), back-scattered electron (BSE), and in-lens detectors. Elemental characterization of the mud samples was done using a Bruker energy dispersive X-ray spectroscopy (EDS) system. 


\subsection{Total mud digestions}

Digestions were conducted to assess the total elemental concentration in the collected mud samples. $0.1 \mathrm{~g}$ of each dried sample was weighed and then digested in $5 \mathrm{~mL}$ of $30 \%$ hydrogen peroxide $\left(\mathrm{H}_{2} \mathrm{O}_{2}\right)$ and $5 \mathrm{~mL}$ of $70 \%$ nitric acid $\left(\mathrm{HNO}_{3}\right.$, ACS certified, Fisher Scientific) at room temperature for 1 hour and then at $120^{\circ} \mathrm{C}$ for an additional 1 hour. Thereafter, $5 \mathrm{~mL}$ of hydrofluoric acid (HF) was added and the samples were heated at $130^{\circ} \mathrm{C}$ for 3.5 hour. The rest of the samples were further dissolved in $20 \mathrm{~mL}$ of $4.5 \%$ boric acid $\left(\mathrm{H}_{3} \mathrm{BO}_{3}\right)$ at $130^{\circ} \mathrm{C}$ for 1 hour to remove any remaining fluoride phases. Subsequently, the samples were filtered through $0.22 \mu \mathrm{m}$ nylon membranes to remove residual organics and diluted 200 times in a mixture of $2 \%$ nitric acid and $0.5 \%$ hydrochloric acid $(\mathrm{HCl})$ for concentration analysis.

\subsection{Leaching experiments}

Mud samples were treated with acid and base to desorb the ions that were naturally adsorbed onto the solid surfaces while in situ. We conducted acid leaches to test the releasable elements at low $\mathrm{pH}$ while the alkaline leaches were designed to assess what elements desorb as the clay particles get transported downstream, where mixing with higher $\mathrm{pH}$ waters occurs. Specifically, $0.5 \mathrm{~g}$ of each sample was suspended in $50 \mathrm{~mL}$ of deionized water to make a $10 \mathrm{~g} / \mathrm{L}$ suspension. The $\mathrm{pH}$ of the suspension was then adjusted to 2 by the addition of $70 \% \mathrm{HNO}_{3}$ to desorb ions into solution. The same treatment was performed at a $\mathrm{pH}$ of 12 using $5 \mathrm{M} \mathrm{NaOH}_{(\mathrm{aq})}$ as an alkaline leach. In both cases, the suspension was then agitated on a tube rotator for $24 \mathrm{~h}$ to achieve equilibrium for surface adsorption/desorption reactions. Afterwards, the suspension was filtered through a $0.22 \mu \mathrm{m}$ nylon membrane to collect the supernatant. 


\subsection{Trace elemental concentration analysis}

The elemental concentration of total digested mud samples, the water samples, and the acid-base leaching samples were analyzed on an Agilent 8800 Triple Quadrupole Inductively Coupled Plasma Mass Spectrometry (ICP-MS) at the Environmental Geochemistry Lab (University of Alberta) using collision and reaction gases to reduce polyatomic interferences after Sakai (2015). The instrument was run in high matrix mode using argon (Ar) gas as the carrier and dilution gas. External calibration was done using a standard fluvial sediment (reference No. STSD-3) with obtained $\mathrm{R}^{2}$ values $>0.992$. Internal standards, measurement modes, and detection limits are summarized in Supplementary Table 1. Based on the trace elemental concentration, the concentration factor of trace elements on mud samples was calculated in a logarithm scale:

$$
\log (\text { concentration factor of element } A)=\log \left(\frac{\text { concentration of element } A \text { in mud }}{\text { concentration of element A in water }}\right)
$$

\subsection{Acid-base titrations}

Acid-base titrations were performed on all 5 mud samples to determine their proton reactivities. Prior to titration, samples were leached with both acid and base (see above procedure) to remove trace elements adsorbed on the surfaces. The samples were rinsed with DI water and then dried in an oven at $60^{\circ} \mathrm{C}$ until constant weight was attained. Potentiometric titrations of the dry mud samples were conducted using an automated continuous titrator (Metrohm Titrando 905). Before each titration, the $\mathrm{pH}$ electrode was calibrated using commercial $\mathrm{pH}$ buffers (Thermo Fisher Scientific; $\mathrm{pH} 4.0,7.0,10.0)$. For each titration, $0.05 \mathrm{~g}$ of each mud was suspended into $50 \mathrm{~mL}$ of $0.01 \mathrm{M}$ sodium nitrate $\left(\mathrm{NaNO}_{3}\right)$ solution, and the suspension was then bubbled for 30 minutes with $\mathrm{N}_{2}(\mathrm{~g})$ to ensure the absence of $\mathrm{CO}_{2}$. During titrations, the experimental apparatus remained sealed and was continually bubbled with $\mathrm{N}_{2}$ to prevent $\mathrm{CO}_{2}$ from entering the system. All mud 
samples were titrated over a $\mathrm{pH}$ range of 3.0 to 10.5 ; initially, a small volume of $0.1 \mathrm{M} \mathrm{HNO}_{3}$ was added to bring $\mathrm{pH}$ to 3.0 , and then $0.1 \mathrm{M}$ sodium hydroxide $(\mathrm{NaOH})$ solution was added incrementally to increase $\mathrm{pH}$ to 10.5 . The volume of acid and base added, and the corresponding $\mathrm{pH}$ change was recorded at each titration step. The $\mathrm{pH}$ was considered stable and recorded only after an electrode stability of $12 \mathrm{mV} / \mathrm{min}$ was achieved.

\section{Results}

\subsection{SEM analyses}

SEM imaging revealed that the mud samples appear generally similar-the majority of the matrix in each sample consists of a disordered mass of aggregates of anhedral clay mineral grains (Figure 2a). Once magnified, the aggregate surfaces appear broken up into $\sim 100 \mathrm{~nm}$ diameter plates and short acicular crystals (Figure 2b). Occasionally, larger clay flakes, up to 100 $\mu \mathrm{m}$ in diameter, were observed (Figure 2c).

Some differences between samples can be deduced in the distribution of $\mathrm{SiO}_{2}$ and $\mathrm{Fe}$ phases. In samples 1, 2 and 5, sub-spherical $\mathrm{SiO}_{2}$-rich particles, 1-2 $\mu \mathrm{m}$ in diameter, appear amongst the clay aggregates, displaying a blotchy surface (probably opal-A, Figures 2d, 2e). Subhedral Fe and Ti-rich grains $>10 \mu \mathrm{m}$ in size were evident in samples 2 and 3 (Figure 2f), and a Fe-S-As phase in sample 5 (Figure 2g). No pyrite particles were visually detected in any sample, although sub-micrometer S-rich particles, bright under BSE mode but too small to reliably analyze via EDS, were found in sample 5 (likely either orpiment or elemental sulfur, Supplementary Figure 3E). Finally, minor As-Sb rich phases were seen in samples 2 and 5, similar to a phase described by Mountain et al. (2001) (Figure 2h).

4.2 Powder X-ray diffraction analysis (XRD) 
The Rietveld refinement plot for mud sample 4 is presented in Figure $3 \mathrm{~A}$ as an example of the XRD pattern for the mud samples; the remaining plots are given in Supplementary Figure 2. Refined mineral abundances for the 5 mud samples are provided in Figure 3B. The minerals identified (in order of most abundant) are kaolinite $\left[\mathrm{Al}_{2} \mathrm{Si}_{2} \mathrm{O}_{5}(\mathrm{OH})_{4}\right]$, montmorillonite $\left[(\mathrm{Na}, \mathrm{Ca})_{0.33}(\mathrm{Al}, \mathrm{Mg})_{2}\left(\mathrm{Si}_{4} \mathrm{O}_{10}\right)(\mathrm{OH})_{2} \cdot \mathrm{nH}_{2} \mathrm{O}\right]$, feldspar [sanidine, $\left.\mathrm{K}\left(\mathrm{AlSi}_{3} \mathrm{O}_{8}\right)\right]$, muscovite and silica (both cristobalite and quartz). All five samples consisted primarily of clay minerals, with $>50 \mathrm{wt} \%$ made up of the dioctahedral clay minerals kaolinite and montmorillonite, except for sample 3 in which these two minerals made up only $38.5 \mathrm{wt} \%$ of the crystalline mass. Sanidine is a major non-clay mineral that was observed in all five mud samples, accounting for between $22.6 \mathrm{wt} \%$ to $34.0 \mathrm{wt} \%$ of the total mineral content (Supplementary Table 2). Muscovite was found at its highest concentrations in sample 3 (up to $24.2 \mathrm{wt} \%$ ). Approximately $3.2 \mathrm{wt} \%$ of quartz was detected in mud sample 2, whereas no quartz was detected in the rest of the samples. Despite micrometer-scale spheres of silica being observed in SEM micrographs (Figure 2d, e), opal was not present at sufficiently high abundance in any of the five samples to permit its quantification using Rietveld refinement with $\mathrm{XRD}$ data. As such, the internal standard $\left(\mathrm{CaF}_{2}\right)$ added to the samples could not be employed for this purpose, and its abundance was normalized out of modal mineralogy results. Many other trace phases $(\ll<1 \mathrm{wt} \%)$ observed during SEM imaging were below detection for our XRD analysis, including Fe-oxide and As-Sb-bearing phases.

\subsection{Elemental composition of mud and water samples}

The major elements in the five mud samples are silicon ( $\mathrm{Si}$ ) and aluminum ( $\mathrm{Al}$ ), with concentrations ranging from 19-24 wt $\%$ and 8-10 wt\%, respectively (Supplementary Table 3). The next most abundant elements are iron (Fe; 2.8-7.9 wt\%), potassium (K; 2.3-4.0 wt\%), 
sodium (Na; 0.1-1.7 wt\%), magnesium (Mg; 0.2-0.7 wt\%) and calcium (Ca; 0.2-0.8 wt\%). Trace elements with concentrations in excess of $100 \mu \mathrm{g} / \mathrm{g}$ are arsenic (As; 136.2-4231.8 $\mu \mathrm{g} / \mathrm{g}$ ), phosphorous (P; 107.5-720.2 $\mu \mathrm{g} / \mathrm{g}$ ), barium (Ba; 285.2-524.6 $\mu \mathrm{g} / \mathrm{g}$ ), lithium (Li; 46.4-232.3 $\mu \mathrm{g} / \mathrm{g}$ ), manganese (Mn; 125.5-227.6 $\mu \mathrm{g} / \mathrm{g}$ ), strontium (Sr; 102.9-191.5 $\mu \mathrm{g} / \mathrm{g}$ ), and zinc ( $\mathrm{Zn}$; 65.6-199.6 $\mu \mathrm{g} / \mathrm{g})$. The concentrations of cadmium (Cd), cerium (Ce), cobalt (Co), chromium (Cr), molybdenum (Mo), lead $(\mathrm{Pb})$ and uranium $(\mathrm{U})$ are all below $100 \mu \mathrm{g} / \mathrm{g}$.

Among the water samples, the $\mathrm{pH}$ varies from 2.42 to 5.84 . The dominant ion is $\mathrm{Na}$ with concentrations ranging from 33.54 to $1126.45 \mathrm{mg} / \mathrm{L}$. It is followed by $\mathrm{K}$ (20.6 to $136.9 \mathrm{mg} / \mathrm{L}$ ), $\mathrm{Ca}(7.9$ to $95.0 \mathrm{mg} / \mathrm{L}), \mathrm{Si}(65.2$ to $113.9 \mathrm{mg} / \mathrm{L})$, As (0.1 to $10.9 \mathrm{mg} / \mathrm{L}), \mathrm{Fe}$ (1.0 to $4.1 \mathrm{mg} / \mathrm{L}), \mathrm{Mg}$ (0.4 to $4.0 \mathrm{mg} / \mathrm{L})$, and $\mathrm{Sr}(0.09$ to $1.6 \mathrm{mg} / \mathrm{L})$. All other elements have concentrations below 1.0 $\mathrm{mg} / \mathrm{L}$, with $\mathrm{Ce}, \mathrm{Co}, \mathrm{Mo}, \mathrm{Pb}$ and $\mathrm{U}$ below $1 \mu \mathrm{g} / \mathrm{L}$. This indicates that they are primarily associated with the solid phase muds, while only a small fraction is dissolved in the aqueous phase (Figure 4).

Mud sample 1 has the highest $\mathrm{Na}, \mathrm{Li}, \mathrm{Zn}$, As, and Ce concentrations amongst the 5 sites sampled. The concentrations of $\mathrm{Li}$ and As in water sample 1 are also the highest, indicating the fluid source of mud pot 1 is enriched in both $\mathrm{Li}$ and As. The relatively lower concentrations of $\mathrm{Na}, \mathrm{Zn}$, and $\mathrm{Ce}$ in water sample 1 compared to other mud samples could be attributed to the adsorption of these elements onto the surfaces of mud sample 1 . The concentrations of $\mathrm{K}, \mathrm{Mn}, \mathrm{Fe}$, and $\mathrm{Pb}$ in mud sample 1 are the lowest among the 5 mud samples, and their corresponding concentrations in water sample 1 are relatively high (compared to other water samples), indicative of the low affinity of these elements to mud surfaces.

The concentrations of $\mathrm{Ca}, \mathrm{Sr}, \mathrm{Ba}$, and $\mathrm{Pb}$ are the highest in mud sample 2 amongst all five mud samples and none of these elements show the highest concentration in water sample 2, 
which is because of their high affinity to solid phase. Intriguingly, sample 2 has the lowest P, As and Mo concentrations in mud, but the highest $\mathrm{P}$ and relatively high As and Mo concentrations in water, indicating the low affinity of anions for mud sample 2.

Mud sample 3 was collected from the highest $\mathrm{pH}$ pool, and correspondingly, it has the highest $\mathrm{Mg}, \mathrm{Cd}, \mathrm{U}$ and relatively high Fe concentrations. The concentrations of $\mathrm{Mg}, \mathrm{Cd}, \mathrm{U}$ and Fe in water sample 3 are the lowest, likely due to the hydrolysis and precipitation or adsorption of these elements on solid surfaces.

Mud sample 4 was collected from the lowest $\mathrm{pH}$ mud pond, and it has relatively high concentrations of anions such as $\mathrm{P}$ and As, but the lowest cation concentrations, including Li, $\mathrm{Na}$, $\mathrm{Mg}, \mathrm{Ca}, \mathrm{Co}, \mathrm{Sr}, \mathrm{Cd}$ and $\mathrm{Ce}$. This is due to the fact that low $\mathrm{pH}$ conditions facilitate anion adsorption but inhibit cation adsorption onto clay surfaces.

Mud sample 5 has the highest $\mathrm{Cr}$, Co and Mo concentrations but the lowest $\mathrm{Zn}$ and $\mathrm{Ba}$ concentrations. Coupled with the relatively low $\mathrm{Zn}$ and $\mathrm{Ba}$ concentrations in water sample 5, this may indicate that the water source of mud pond 5 has low $\mathrm{Zn}$ and Ba concentrations.

\subsection{Acid-base leaching results}

During acid-base leaching, the elemental concentrations in the supernatants were measured and converted into $\mu \mathrm{g}$ of element per $\mathrm{g}$ of mud sample based on the mud-liquid ratio (Supplementary Table 4). We applied the following equation to calculate the percentage of weakly bound elements in mud samples:

$\%$ of weakly bound elements $=\frac{\mu \mathrm{g} \text { of element released per g of mud sample during acid-base leaching }}{\mu \mathrm{g} \text { of element per g of mud sample prior to leaching }} * 100 \%$

(eq. 1) 
The results are listed in Table 2. Amongst the elements studied, $\mathrm{Li}, \mathrm{Na}$, and $\mathrm{Ca}$ are most prone to leaching under acidic conditions. Almost half of the As was released under acidic conditions for samples 1 and 2, while 25.9 and $10.2 \%$ was released for samples 3 and 5, and only $0.5 \%$ for sample 4. Cadmium in samples 1 and 2 was desorbed almost fully in acid but only 6.0\%, 0\% (below detection limit), and 38.78\% were desorbed in sample 3, 4, 5, respectively. Similarly, over $50 \%$ of $\mathrm{Ca}$ in samples 1,4 , and $5(61.5 \%, 97.2 \%$, and $64.8 \%$, respectively) was desorbed under acidic treatment, but only $29.2 \%, 46.6 \%$ for sample 2 and 3, respectively. Molybdenum in samples 1, 2, and 3 was susceptible to acidic leaching $(71.7 \%, 100 \%$, and $96.1 \%$, respectively), while in samples 4,5 , the percentage was only $19.1 \%$ and $6.1 \%$. The release of $\mathrm{P}$ at low $\mathrm{pH}$ was relatively minor with only $7.4 \%, 28.6 \%, 33.6 \%, 8.8 \%$, and $35.9 \%$ released for samples 1 to 5 .

The alkaline treatment released $77.9 \%$ of the As from sample 1 and $48.2 \%$ from sample 2, compared to $25.8 \%, 18.4 \%$, and $18.6 \%$ from samples 3 , 4, and 5, respectively. Cadmium release under alkaline treatment ranged from $22.8-38.8 \%$ for the five samples which was lower than acidic treatment. The same behavior was observed for $\mathrm{Ca}$ with alkaline treatment, only releasing less than $10 \%$ of Ca from the 5 mud samples (except $11.7 \%$ for sample 4 ). The release of Mo for all 5 studied samples ranged from $17.0 \%$ to $39.9 \%$ under high $\mathrm{pH}$ condition. Phosphorus is more easily released under alkaline conditions with the $\mathrm{pH} 12$ solution releasing $51.1 \%$ of the $\mathrm{P}$ in sample 5, and $37.5 \%, 31.2 \%, 22.9 \%$, and $31.5 \%$ in samples 1 to 4 , respectively.

The other elements ( $\mathrm{U}, \mathrm{Pb}, \mathrm{Ce}, \mathrm{Fe}, \mathrm{Si}, \mathrm{Al}$, and $\mathrm{Mg}$ ) were all rather immobile (less than $10 \%$ desorption) under both acid and base leaching, suggesting they are associated strongly with the solid phase, possibly forming inner-sphere complexes or residing within the crystal structures of minerals rather than being adsorbed to mineral surfaces. 


\subsection{Titration and surface complexation modeling (SCM)}

SCM was used to model the protonation-deprotonation behavior of functional groups on the surfaces of minerals in mud samples as a function of solution $\mathrm{pH}$. Since the mud samples are mostly composed of clay minerals, we applied the same model for protonation and deprotonation surface reactions as used in previous clay studies (Barbier et al., 2000a; Lackovic et al., 2003; Ikhsan et al., 2005; Peacock and Sherman, 2005; Hao et al., 2018; Hao et al., 2019a). The following surface complexation reactions and corresponding mass action equations were used:

$$
\begin{gathered}
\equiv \mathrm{LNa}+\mathrm{H}^{+} \leftrightarrow \equiv \mathrm{LH}+\mathrm{Na}^{+} \\
\mathrm{K}=\frac{[\equiv \mathrm{LH}] \bullet \alpha_{\mathrm{Na}^{+}}}{[\equiv \mathrm{LNa}] \bullet \alpha_{\mathrm{H}^{+}}} \\
\equiv \mathrm{XOH} \leftrightarrow \mathrm{H}^{+}+\equiv \mathrm{XO}^{-} \\
\mathrm{K}_{\mathrm{a}-}=\frac{\left[\equiv \mathrm{XO}^{-}\right] \bullet \alpha_{\mathrm{H}^{+}}}{[\equiv \mathrm{XOH}]} \\
\equiv \mathrm{XOH}+\mathrm{H}^{+} \leftrightarrow \equiv \mathrm{XOH}_{2}^{+} \\
\mathrm{K}_{\mathrm{a}+}=\frac{\left[\equiv \mathrm{XOH}{ }_{2}^{+}\right]}{[\equiv \mathrm{XOH}] \bullet \alpha_{\mathrm{H}^{+}}}
\end{gathered}
$$

The $\equiv$ LNa site represents surface functional groups generated by isomorphic substitution which have an inherent negative charge, while $\equiv \mathrm{XOH}$ indicates amphoteric $\equiv \mathrm{Al}-\mathrm{OH}$ or $\equiv \mathrm{Si}-\mathrm{OH}$ groups that can either protonate or deprotonate.

The modeled surface functional group densities and protonation constants $\left(\log \mathrm{K}, \log \mathrm{K}_{\mathrm{a}+}\right.$, $\log \mathrm{K}_{\mathrm{a}-}$ ) are given in Table 3. Briefly, the site density of the $\equiv \mathrm{LH}$ group is higher than that of the $\equiv \mathrm{XOH}$ group, which ranges from $1.14 \times 10^{-4}$ to $1.83 \times 10^{-4} \mathrm{~mol} / \mathrm{g}$ for the $\equiv \mathrm{LH}$ group compared to $5.23 \times 10^{-5}$ to $1.36 \times 10^{-4} \mathrm{~mol} / \mathrm{g}$ for the $\equiv \mathrm{XOH}$ group. There is little discrepancy in the ion exchange reactions of $\equiv \mathrm{LH}$ groups amongst the five studied samples, with $\operatorname{logK}$ values ranging from 3.64 to 3.79 . However, $\log \mathrm{K}_{\mathrm{a}-}$ is greater for samples 1,4 and $5(-10.22,-9.60$, and -10.60 , 
respectively) than for samples 2 and 3 (-11.74 and -11.59 , respectively). Sample 3 has the highest $\log \mathrm{K}_{\mathrm{a}+}(9.27)$, followed by sample 2 (8.83), while samples 1,2 , and 4 have relatively lower $\log \mathrm{K}_{\mathrm{a}+}(8.64,8.06$, and 8.81).

The variation of surface functional group speciation with solution $\mathrm{pH}$ is illustrated in Figure 6. Generally, $\equiv \mathrm{LH}$ and $\equiv \mathrm{XOH}_{2}{ }^{+}$species dominate at low $\mathrm{pH}$ conditions $(\mathrm{pH}=3-5)$, but the $\equiv \mathrm{LH}$ group begins undergoing an ion exchange reaction with $\mathrm{Na}^{+}$at $\mathrm{pH}$ around 5 and $\equiv \mathrm{LNa}$ species begin to dominate at $\mathrm{pH}$ higher than 7 . The surface $\equiv \mathrm{XOH}$ group is highly protonated as $\equiv \mathrm{XOH}_{2}{ }^{+}$over a wide $\mathrm{pH}$ range ( $\mathrm{pH}=3$ to approximately 8 ). At $\mathrm{pH}$ higher than 8 , aqueous species $\equiv \mathrm{XOH}$ and $\equiv \mathrm{XO}^{-}$begin to dominate; however, the $\mathrm{pK}_{\mathrm{a}}$ values of the second deprotonation reaction vary widely between 9.6 and 11.7 . Thus, over the titrated $\mathrm{pH}$ range, the $\equiv \mathrm{XO}^{-}$species is of minor importance in samples 2 and 3 but becomes important in samples 1,4 and 5 at $\mathrm{pH}>9$. This indicates that the $\equiv \mathrm{XOH}$ group in samples 2 and 3 has a higher proton affinity than in samples 1,4 and 5 .

\section{Discussion}

5.1 The mineralogy of the ETGF mud samples

El Tatio geothermal field is situated in the volcanically active, Quaternary-age Altiplano-Puña Volcanic Complex of the Central Volcanic Zone in northern Chile, and major host rock of the Tatio basin is comprised primarily of a $\sim 1-\mathrm{km}$-thick of ignimbrites, tuffs and lavas with dacitic composition (Healy, 1973; Lahsen and Trujillo, 1976; Lahsen, 1988; De Silva et al., 1994). This is consistent with the observed occurrence of felsic volcanic minerals such as sanidine, muscovite and cristobalite in mud pots sampled for this study, and this composition can be considered representative of mud pots found throughout the Upper and Middle (Group M-III) 
Basins of the geothermal field. The main geothermal field is covered by a relatively thin (1-totens-of-meters-thick) silica sinter platform formed during recent geothermal activity (Nicolau et al., 2014; Munoz-Saez et al., 2016; Wilmeth et al., 2020), overlying the deep dacitic ignimbrite aquifer (Cusicanqui et al., 1976; Tassi et al., 2010). Although the precise source of As in geothermal fluids is unknown, $\mathrm{As}: \mathrm{Cl}$ ratios in fluids are conservative, indicating steady leaching from the host rock at high temperatures in the aquifer (Landrum et al., 2009). This process may be analogous to the high degree of As leaching observed in natural and experimental samples examined during this study. These results shed light on the importance of dacitic volcanic deposits, and the process of leaching as a regional source of As contamination in Region II, Chile.

\subsection{Concentration factors and inherent element behavior}

The concentration factor of trace elements on mud samples (logarithm of concentration in mud / concentration in water) are presented in Figure 4. All elements are highly enriched in muds with a $\log$ scale concentration factor of $>1$ (indicating $>10$ times enrichment in the mud phase relative to the liquid phase) for most of the elements. Specifically, the concentration factors of $\mathrm{Ce}, \mathrm{Al}, \mathrm{U}$, and $\mathrm{Fe}$ are higher than 4 (>10,000 times enrichment) for most of the samples, and low concentration factors are observed for $\mathrm{Na}$ and $\mathrm{Li}$ (lower than 1). Elements such as $\mathrm{Pb}, \mathrm{P}, \mathrm{As}, \mathrm{Mo}$ have concentration factors around 2-4 (100-10000 times enrichment). Except for $\mathrm{Al}$ (which is a structural element in clays), Ce is highly enriched in the mud phase, due to the irreversible adsorption of Ce onto clay minerals and the formation of 12 inner-sphere covalent bonds with $\mathrm{O}$ on clay surfaces (Fuller et al., 2015). Ferric iron usually precipitates on the surfaces of mud samples and forms ferric hydroxides containing As and S (Supplementary Figure 3E). Uranium adsorption onto clay minerals is $\mathrm{pH}$ dependent, being higher at neutral to high $\mathrm{pH}$ but lower at acidic pH (Bachmaf and Merkel, 2011). This adsorption behavior explains the lower 
concentration factor in sample 4 (collected at $\mathrm{pH} 2.42$, Table 1) than samples $1,2,3$ and 5 (collected at $\mathrm{pH}$ from 3.55 to 5.84, Table 1). Monovalent ions, such as $\mathrm{Li}^{+}$and $\mathrm{Na}^{+}$, are exchangeable on clay interlayers, and show relatively lower concentration factors in mud samples. By comparison, $\mathrm{K}$ is relatively enriched compared to $\mathrm{Li}$ and $\mathrm{Na}$ because it is relatively stable in muscovite interlayers and, therefore, resistant to exchange (Scott and Smith, 1966).

Elemental concentration factors in each mud sample were compared with the average of all five samples (concentration factor of each element in every mud sample /average concentration factor of the element in all 5 samples;Figure 5). Mud sample 1 has high concentration factors for $\mathrm{U}, \mathrm{Mo}, \mathrm{P}$, and $\mathrm{Co}$, but low concentration factors for $\mathrm{Mg}, \mathrm{Ba}, \mathrm{Mn}, \mathrm{K}, \mathrm{Sr}$, $\mathrm{Ca}, \mathrm{Li}, \mathrm{Na}$, and $\mathrm{Cd}$. Similarly, sample 4 has high concentration factors for $\mathrm{P}$ and As, but low concentration factors for $\mathrm{U}, \mathrm{Ce}, \mathrm{Mo}, \mathrm{Zn}, \mathrm{Mg}, \mathrm{Mn}, \mathrm{Sr}, \mathrm{Ca}$. Both mud samples show high affinities to anions like $\mathrm{P}$ and $\mathrm{As}$, but low affinities to cations like $\mathrm{Mg}, \mathrm{Mn}, \mathrm{Sr}$ and $\mathrm{Ca}$. Such behavior can be attributed to the fact that samples 1 and 4 were collected at low $\mathrm{pH}$ ponds $(\mathrm{pH}=3.55$ and 2.42 , respectively), and at low $\mathrm{pH}$ conditions clay surfaces are protonated, which repulses cations but attracts anions (Sposito et al., 1999; Lützenkirchen et al., 2012). By contrast, samples 2 and 3 were collected at relatively higher $\mathrm{pH}$ ponds ( $\mathrm{pH}=4.87$ and 5.84, respectively), and both samples have low concentration factors for anions such as Mo, P and As, but high concentration factors for cations such as $\mathrm{Cd}, \mathrm{Na}$ and $\mathrm{Ca}$. These trends support a $\mathrm{pH}$-control mechanism, mimicking the natural trend of $\mathrm{pH}$ increase from source-to-sink, for trace elemental enrichment. Sample 5 was collected at a mud pond with $\mathrm{pH}=4.01$, and has high concentration factors for $\mathrm{Pb}, \mathrm{Mo}, \mathrm{Mg}, \mathrm{Mn}$, $\mathrm{K}, \mathrm{Sr}, \mathrm{Ca}$ and $\mathrm{Li}$, but low concentration factors for $\mathrm{Co}$ and $\mathrm{Cd}$.

5.3 Element mobility during experimental $\mathrm{pH}$ change: mimicking downstream transport 
The acid-base leaching experiments largely confirm the findings above in that solution $\mathrm{pH}$ ultimately dictates elemental sorption to clay minerals. Indeed, a large fraction of the elements analyzed are prone to dissociate in response to environmental $\mathrm{pH}$ variation, especially $\mathrm{P}, \mathrm{Ca}, \mathrm{Co}$, $\mathrm{Sr}$, As, Mo, and Cd. The differences in mobility can be explained through different modes of occurrence (e.g., adsorption and precipitation) of elements in the mud samples. For example, $\mathrm{Cd}$ only desorbs from mud surfaces under more acidic conditions (acidic treatment releases more $\mathrm{Cd}$ compared to alkaline treatment, Table 2), which agrees with our previous findings that $\mathrm{Cd}$ primarily forms outer-sphere complexes under acidic conditions, but inner-sphere complexes under alkaline conditions (Hao et al., 2020). Similarly, $\mathrm{Ca}$ is mostly an exchange cation at clay interlayers which can be replaced and released back into solution at low $\mathrm{pH}$ conditions, but precipitates on clay surfaces as calcium hydroxide at high $\mathrm{pH}$ conditions. Previous studies showed that the adsorption of $\mathrm{Co}$ and $\mathrm{Sr}$ onto kaolinite increases with solution $\mathrm{pH}$ (Angove et al., 1998; Jeong, 2001), which explains why Co and Sr desorbed more under acidic treatment than alkaline treatment in our leaching experiments (Table 2).

By comparison, $\mathrm{P}$ accumulates on clay minerals at low pH (Gérard, 2016), and at high $\mathrm{pH}$, the release of $\mathrm{P}$ from the mud surfaces is expected. Such adsorption behavior on clay minerals can also be observed for anions like As (Goldberg, 2002), which corresponds to our experimental results that As is preferentially released under alkaline conditions compared to acidic conditions (except for sample 2). It is also worth noting that the adsorption of Mo onto clay minerals decreases with increasing $\mathrm{pH}$ (Goldberg et al., 1996), but our experimental results show only $30 \%$ to $40 \%$ of Mo released for sample 2 and 3 under alkaline treatment but almost $100 \%$ of Mo release under acidic treatment. This could possibly be attributed to the dissolution of minor Mo minerals (which are below the detection limit of XRD) under acidic conditions. 
In contrast with the above elements, $\mathrm{Cr}$ and $\mathrm{U}$ are immobile when subject to environmental $\mathrm{pH}$ variations. This is probably because the interaction between $\mathrm{Cr}$ and clay minerals is through strong inner-sphere bonding — our recent experimental study of $\mathrm{Cr}$ binding onto clay minerals using Extended X-ray Absorption Fine Structure (EXAFS) spectroscopy analysis showed that $\mathrm{Cr}$ adsorption could lead to isomorphic substitution of $\mathrm{Al}$ with $\mathrm{Cr}$ on octahedral sheets at the surfaces of clay minerals (Hao et al., 2021, in review). Similarly, in all 5 mud samples, $\mathrm{U}$ is resistant to being released from clay minerals surfaces over the tested range of $\mathrm{pH}$ (Table 2), which is possibly due to its inner-sphere complexation onto clay minerals (Catalano and Brown, 2005; Krepelova et al., 2008; Schlegel and Descostes, 2009).

\subsection{Surface acid-base properties of the ETGF mud samples}

The results of SCMs of acid-base titration data from ETGF mud samples (Table 3) are within the range of previously published proton binding constants and site concentrations for clay minerals (Baeyens and Bradbury, 1997; Barbier et al., 2000b; Gu and Evans, 2007; Gu and Evans, 2008; Gu et al., 2010; Hao et al., 2019a). Amongst our ETGF samples, sample 4 was collected from the lowest $\mathrm{pH}$ environment and has the lowest $\log \mathrm{K}$ (3.64) and $\log \mathrm{K}_{\mathrm{a}+}$ (8.06) but highest $\log \mathrm{K}_{\mathrm{a}-}(-$ 9.60), which indicates that the acidic environment can lower the proton affinities of mineral surfaces. The overall surface functional group density of sample 4 is relatively low when compared to the other 4 samples. These data correspond to a previous study which showed that acidic treatment on clay minerals can decrease $\mathrm{pK}_{\mathrm{a}}$ values and surface functional group density (Jeon and Nam, 2019).

The surface functional group protonation diagrams for ETGF samples (Figure 6) indicate that ion exchange reactions on $\equiv \mathrm{LH}$ primarily occur between $\mathrm{pH}$ values of 5 to 6 , where aqueous 
cations (such as $\mathrm{Na}$, and $\mathrm{Li}$ ) can exchange with the interlayer of smectites. This can explain why a large portion of $\mathrm{Li}$ and $\mathrm{Na}$ can be released during acidic treatment (Table 2). Acidic leaching can result in significant cation release from the interlayers of clay minerals such as smectites, as evident in the leaching experiments with $\mathrm{Na}, \mathrm{Ca}, \mathrm{Co}, \mathrm{Sr}$, and $\mathrm{Ba}$, where the protonation of amphoteric silanol and aluminol groups to $\equiv \mathrm{XOH}_{2}{ }^{+}$causes them to become repulsive to cations. While a highly protonated $\equiv \mathrm{XOH}_{2}{ }^{+}$surface speciation at lower $\mathrm{pH}$ attracts anions, when solution $\mathrm{pH}$ increases to values of 8 to $9, \equiv \mathrm{XOH}_{2}{ }^{+}$progressively deprotonates to neutrally charged or negatively charged surface species. This then facilitates the desorption of anions, such as $\mathrm{P}$ and As, from clay mineral surfaces. As mentioned above, there may be minor mineral dissolution at low $\mathrm{pH}$, which could also lead to trace elemental release.

Based on the estimates of surface site density, the maximum concentrations of elements that can be adsorbed are $1.87 \times 10^{-4}, 1.7 \times 10^{-4}, 1.97 \times 10^{-4}, 1.68 \times 10^{-4}$, and $2.01 \times 10^{-4} \mathrm{~mol} / \mathrm{g}$ (the sum of concentrations for both sites) for the five mud samples, respectively. Normally adsorbed elements are weakly bound and subject to desorption if solution $\mathrm{pH}$ changes. However, during acid-base leaching experiments, we observed slightly more elemental release, for example, the sum of elemental release in acid and base treatment is $12.90 \times 10^{-4}, 5.35 \times 10^{-4}, 7.32 \times 10^{-4}, 4.27 \times 10^{-}$ ${ }^{4}, 3.79 \times 10^{-4} \mathrm{~mol} / \mathrm{g}$ for the 5 mud samples respectively (see Supplementary Table 6 ). While some of the elements would be released under both acidic and alkaline conditions, we attribute the extra release of elements to the dissolution of minor minerals as discussed above.

\section{Implications}

The El Tatio geothermal field effluent drains westward to form the major headwaters for Region II, Chile (e.g., Rio Salado, which flows into the Rio Loa), containing high concentrations of Li, 
As, Mo, and Cd sourced from the geothermal water (Romero et al., 2003). Previous work focused on downstream attenuation of As via adsorption onto iron oxide surfaces (Romero et al., 2003; Landrum et al., 2009); however, our results show that these elements are also highly prone to be released from clay minerals into solution when subjected to upward environmental $\mathrm{pH}$ shifts on its journey from acidic sources, to circumneutral geothermal drainages, and eventually, alkaline seawater. Focusing specifically on As, previous sequential extraction analyses have shown that $\sim 20 \%$ of As in Rio Loa Basin sediments is present in adsorbed fractions that readily exchange with water (Romero et al., 2003). We suggest that mud-bound As plays an important part of this readily-exchanged fraction, and the release of weakly bound As from mud surfaces could contribute to the high concentration of As in the fluvial basin. For example, the suspension of $0.5 \mathrm{~g} / \mathrm{L}$ of mud sample 1 (which has $4.2 \mathrm{mg}$ of As per $\mathrm{g}$ of mud, $77.88 \%$ of which will be released as $\mathrm{pH}$ rises) in rivers will result in $1.65 \mathrm{mg} / \mathrm{L}$ of As in rivers, which is close to the As concentration in Rio Salado (1.1-1.2 mg/L; Romero et al., 2003). Due to the lack of dilution by freshwater in the Atacama Desert (Capaccioni et al., 2009), As contamination in Rio Salado can be traced several hundreds of km downstream - the lower part of Rio Loa has As concentrations ranging from 1.82-2.40 mg/L (Bugueño et al., 2014). It is worth noting that previous studies showed that the $\mathrm{pH}$ of river water in the ETGF area stays between 7 and 8 throughout the drainage basin (Romero et al., 2003), which indicates that the As desorption will occur in situ once the more acidic, As-bearing mud encounters relatively dilute, circumneutral river water, and the dissolved As will travel downstream.

Our research highlights how clay minerals can accumulate trace elements (such as As, P, $\mathrm{Cd}, \mathrm{Ca}, \mathrm{Co}, \mathrm{Sr}$ and $\mathrm{Mo}$ ) in hydrothermal hot springs and subsequently release them into aqueous solution with variations in environmental conditions. These findings confirm that the reactive 
and dynamic character of clay mineral surfaces affects aqueous chemistry in complex natural settings. Therefore, a nuanced assessment of the solid phase trace elements budget must be considered crucial in investigating environmental nutrient and pollutant fluxes.

\section{Acknowledgments}

This work was supported by NSERC Discovery Grants to KOK (RGPIN-165831), DSA (RGPIN-04134) and SAW (RGPIN-04368/RGPAS-00064). HWD gratefully acknowledges the support of China Scholarship Council (CSC, No. 201506420044). MVZ acknowledges support from the European Research Council, under the European Union's Horizon 2020 research and innovation programme (grant agreement no. 694894). Thanks to Rebecca Funk for collecting

XRD patterns in the Department of Earth and Atmospheric Sciences X-ray Diffraction Laboratory.

\section{References}

Alsina, M.A. et al., 2014. Arsenic speciation in sinter mineralization from a hydrothermal channel of El Tatio geothermal field, Chile. Journal of hydrology, 518: 434-446.

Angove, M.J., Johnson, B.B., Wells, J.D., 1998. The Influence of Temperature on the Adsorption of Cadmium(II) and Cobalt(II) on Kaolinite. Journal of Colloid and Interface Science, 204(1): 93-103.

Bachmaf, S., Merkel, B.J., 2011. Sorption of uranium(VI) at the clay mineral-water interface. Environmental Earth Sciences, 63(5): 925-934.

Baeyens, B., Bradbury, M.H., 1997. A mechanistic description of $\mathrm{Ni}$ and $\mathrm{Zn}$ sorption on $\mathrm{Na-}$ montmorillonite .1. Titration and sorption measurements. Journal of Contaminant Hydrology, 27(3-4): 199-222.

Barbier, F., Duc, G., Petit-Ramel, M., 2000a. Adsorption of lead and cadmium ions from aqueous solution to the montmorillonite/water interface. Colloids and Surfaces A: Physicochemical and Engineering Aspects, 166(1-3): 153-159.

Barbier, F., Duc, G., Petit-Ramel, M., 2000b. Adsorption of lead and cadmium ions from aqueous solution to the montmorillonite/water interface. Colloids and Surfaces A: physicochemical and engineering aspects, 166(1): 153-159.

Bish, D.L., Carey, J.W., Vaniman, D.T., Chipera, S.J., 2003. Stability of hydrous minerals on the martian surface. Icarus, 164(1): 96-103.

Bish, D.L., Howard, S.A., 1988. Quantitative phase-analysis using the rietveld method. Journal of Applied Crystallography, 21: 86-91. 
Bradbury, M.H., Baeyens, B., 2002. Sorption of Eu on Na- and Ca-montmorillonites: Experimental investigations and modelling with cation exchange and surface complexation. Geochimica et Cosmochimica Acta, 66(13): 2325-2334.

Bradbury, M.H., Baeyens, B., 2009. Sorption modelling on illite Part I: Titration measurements and the sorption of $\mathrm{Ni}, \mathrm{Co}$, Eu and Sn. Geochimica et Cosmochimica Acta, 73(4): 990-1003.

Bugueño, M.P., Acevedo, S.E., Bonilla, C.A., Pizarro, G.E., Pasten, P.A., 2014. Differential arsenic binding in the sediments of two sites in Chile's lower Loa River basin. Science of The Total Environment, 466-467: 387-396.

Capaccioni, B., Rossi, P.I., Tassi, F., Aguilera, F., 2009. Origin and environmental impact of fluid discharges from the El Tatio geothermal field (Antofagasta region, Northern Chile). Geological constraints on the onset and evolution of an extreme environment: The Atacama area, GeoActa Special Publication, 2: 59-73.

Cardenas, M.B., Engel, A.S., 2012. Archaea at the El Tatio Geyser Field: community composition, diversity, and distribution across hydrothermal features and geochemical gradients.

Catalano, J.G., Brown, G.E., 2005. Uranyl adsorption onto montmorillonite: Evaluation of binding sites and carbonate complexation. Geochimica Et Cosmochimica Acta, 69(12): 2995-3005.

Cheary, R.W., Coelho, A., 1992. A fundamental parameters approach to x-ray line-profile fitting. Journal of Applied Crystallography, 25: 109-121.

Cortecci, G. et al., 2005. New chemical and original isotopic data on waters from El Tatio geothermal field, northern Chile. Geochemical Journal, 39(6): 547-571.

Cultrone, G., Rodriguez-Navarro, C., Sebastian, E., Cazalla, O., De La Torre, M.J., 2001. Carbonate and silicate phase reactions during ceramic firing. European Journal of Mineralogy, 13(3): 621-634.

Cusicanqui, H., Mahon, W.A.J., Ellis A.J., 1976. The geochemistry of the El Tatio geothermal field, Northern Chile.

De Silva, S., 1989. Altiplano-Puna volcanic complex of the central Andes. Geology, 17(12): 1102-1106.

De Silva, S.L., Francis, P., 1991. Volcanoes of the central Andes, 219. Springer-Verlag Berlin.

De Silva, S., Self, S., Francis, P., Drake, R., Carlos, R.R., 1994. Effusive silicic volcanism in the Central Andes: The Chao dacite and other young lavas of the Altiplano-Puna Volcanic Complex. Journal of Geophysical Research: Solid Earth, 99(B9): 17805-17825.

Ellis, A., 1969. Survey for geothermal development in Northern Chile. Preliminary geochemistry report, El Tatio geothermal field. UNDP-Report.

Ellis, A., Mahon, W., 1964. Natural hydrothermal systems and experimental hot-water/rock interactions. Geochimica et Cosmochimica Acta, 28(8): 1323-1357.

Ellis, A., Mahon, W., 1967. Natural hydrothermal systems and experimental hot water/rock interactions (Part II). Geochimica et Cosmochimica Acta, 31(4): 519-538.

Engel, A.S., Johnson, L.R., Porter, M.L., 2013. Arsenite oxidase gene diversity among C hloroflexi and P roteobacteria from El Tatio Geyser Field, Chile. FEMS microbiology ecology, 83(3): 745-756.

Escudero, L.V., Casamayor, E.O., Chong, G., Pedrós-Alió, C., Demergasso, C., 2013. Distribution of microbial arsenic reduction, oxidation and extrusion genes along a wide range of environmental arsenic concentrations. PLoS One, 8(10): e78890.

Fernandez-Turiel, J.L., Garcia-Valles, M., Gimeno-Torrente, D., Saavedra-Alonso, J., Martinez-Manent, S., 2005. The hot spring and geyser sinters of El Tatio, Northern Chile. Sedimentary Geology, 180(3): 125-147.

Fuller, A.J. et al., 2015. Caesium incorporation and retention in illite interlayers. Applied Clay Science, 108: 128-134.

Garcia-Valles, M., Fernandez-Turiel, J., Gimeno-Torrente, D., Saavedra-Alonso, J., Martinez-Manent, S., 2008. Mineralogical characterization of silica sinters from the El Tatio geothermal field, Chile. American Mineralogist, 93(8-9): 1373-1383. 
Gérard, F., 2016. Clay minerals, iron/aluminum oxides, and their contribution to phosphate sorption in soils - A myth revisited. Geoderma, 262: 213-226.

Giggenbach, W.F., 1978. The isotopic composition of waters from the El Tatio geothermal field, Northern Chile. Geochimica et Cosmochimica Acta, 42(7): 979-988.

Glennon, J.A., Pfaff, R.M., 2003. The extraordinary thermal activity of El Tatio geyser field, Antofagasta Region, Chile. GOSA Trans, 8: 31-78.

Goldberg, S., 2002. Competitive adsorption of arsenate and arsenite on oxides and clay minerals. Soil Science Society of America Journal, 66(2): 413-421.

Goldberg, S., Forster, H., Godfrey, C., 1996. Molybdenum adsorption on oxides, clay minerals, and soils. Soil Science Society of America Journal, 60(2): 425-432.

Gong, J. et al., 2019. Formation and Preservation of Microbial Palisade Fabric in Silica Deposits from El Tatio, Chile. Astrobiology, 20(4): 500-524.

$\mathrm{Gu}, \mathrm{X}$., Evans, L.J., 2007. Modelling the adsorption of $\mathrm{Cd}(\mathrm{II}), \mathrm{Cu}(\mathrm{II}), \mathrm{Ni}(\mathrm{II}), \mathrm{Pb}(\mathrm{II})$, and $\mathrm{Zn}(\mathrm{II})$ onto Fithian illite. Journal of colloid and interface science, 307(2): 317-25.

$\mathrm{Gu}$, X., Evans, L.J., 2008. Surface complexation modelling of $\mathrm{Cd}(\mathrm{II}), \mathrm{Cu}(\mathrm{II}), \mathrm{Ni}(\mathrm{II}), \mathrm{Pb}(\mathrm{II})$ and $\mathrm{Zn}(\mathrm{II})$ adsorption onto kaolinite. Geochimica et Cosmochimica Acta, 72(2): 267-276.

$\mathrm{Gu}, \mathrm{X}$., Evans, L.J., Barabash, S.J., 2010. Modeling the adsorption of Cd (II), Cu (II), Ni (II), Pb (II) and Zn (II) onto montmorillonite. Geochimica et Cosmochimica Acta, 74(20): 5718-5728.

Hao, W., Flynn, S.L., Alessi, D.S., Konhauser, K.O., 2018. Change of the point of zero net proton charge (pHPZNPC) of clay minerals with ionic strength. Chemical Geology, 493: 458-467.

Hao, W. et al., 2019a. The impact of ionic strength on the proton reactivity of clay minerals. Chemical Geology: 119294.

Hao, W. et al., 2019b. Effect of acidic conditions on surface properties and metal binding capacity of clay minerals. ACS Earth and Space Chemistry.

Hao, W. Kashiwabara, T., Jin, R., Takahashi, Y., Gingras, M., Alessi, D.S., Konhauser, K.O., 2020. Clay minerals as a source of cadmium to esturies. Scientific Reports. 10, 10417.

Hao, W. et al., 2021. Experimental study of the occurrence of chromium (III) in clay minerals: Implications for the enrichment of $\mathrm{Cr}$ in laterites. Geology, in review

Haselton Jr, H., Cygan, G., Jenkins, D., 1995. Experimental study of muscovite stability in pure $\mathrm{H} 2 \mathrm{O}$ and 1 molal KCl-HCl solutions. Geochimica et Cosmochimica Acta, 59(3): 429-442.

Healy, J., Hochstein, M., 1973. Horizontal flow in hydrothermal systems. Journal of Hydrology (New Zealand): 71-82.

Hill, R.J., Howard, C.J., 1987. Quantitative phase-analysis from neutron powder diffraction data using the rietveld method. Journal of Applied Crystallography, 20: 467-474.

Huang, W., Wyllie, P., 1973. Muscovite dehydration and melting in deep crust and subducted oceanic sediments. Earth and planetary science letters, 18(1): 133-136.

Ikhsan, J., Wells, J.D., Johnson, B.B., Angove, M.J., 2005. Surface complexation modeling of the sorption of Zn(II) by montmorillonite. Colloids and Surfaces A: Physicochemical and Engineering Aspects, 252(1): 33-41.

Jeon, I., Nam, K., 2019. Change in the site density and surface acidity of clay minerals by acid or alkali spills and its effect on pH buffering capacity. Scientific Reports, 9(1): 9878.

Jeong, C.H., 2001. Mineralogical and hydrochemical effects on adsorption removal of cesium-137 and strontium-90 by kaolinite. Journal of Environmental Science and Health, Part A, 36(6): 10891099.

Krepelova, A., Reich, T., Sachs, S., Drebert, J., Bernhard, G., 2008. Structural characterization of U(VI) surface complexes on kaolinite in the presence of humic acid using EXAFS spectroscopy. Journal of Colloid and Interface Science, 319(1): 40-47. 
Lackovic, K., Angove, M.J., Wells, J.D., Johnson, B.B., 2003. Modeling the adsorption of Cd(II) onto Muloorina illite and related clay minerals. Journal of Colloid and Interface Science, 257(1): 31-40.

Lahsen, A., 1988. Chilean geothermal resources and their possible utilization. Geothermics, 17(2-3): 401410.

Lahsen, A., Trujillo, P., 1976. The geothermal field of El Tatio, Chile, Proceeding, Second United Nations Symposium on the Development and Use of Geothermal Resources, San Francisco, pp. 170-177.

Landrum, J.T. et al., 2009. Partitioning geochemistry of arsenic and antimony, El Tatio Geyser Field, Chile. Applied Geochemistry, 24(4): 664-676.

Landry, C.J., Koretsky, C.M., Lund, T.J., Schaller, M., Das, S., 2009. Surface complexation modeling of Co(II) adsorption on mixtures of hydrous ferric oxide, quartz and kaolinite. Geochimica et Cosmochimica Acta, 73(13): 3723-3737.

Leiva, E.D. et al., 2014. Natural attenuation process via microbial oxidation of arsenic in a high Andean watershed. Science of the total environment, 466: 490-502.

Liu, C.-C. et al., 2009. Geochemical characteristics of the fluids and muds from two southern Taiwan mud volcanoes: Implications for water-sediment interaction and groundwater arsenic enrichment. Applied Geochemistry, 24(9): 1793-1802.

Liu, Y. et al., 2018. Acid-base properties of kaolinite, montmorillonite and illite at marine ionic strength. Chemical Geology, 483: 191-200.

Locock, A.J., Chesterman, D., Caird, D., Duke, M.J.M., 2012. Miniaturization of mechanical milling for powder X-ray diffraction. Powder Diffraction, 27(3): 189-193.

Lützenkirchen, J. et al., 2012. Potentiometric Titrations as a Tool for Surface Charge Determination. Croatica Chemica Acta, 85(4): 391-417.

Magaritz, M., Aravena, R., Peña, H., Suzuki, O., Grilli, A., 1990. Source of ground water in the deserts of northern Chile: evidence of deep circulation of ground water from the Andes. Groundwater, 28(4): 513-517.

Mervine, E.M. et al., 2018. Potential for offsetting diamond mine carbon emissions through mineral carbonation of processed kimberlite: an assessment of De Beers mine sites in South Africa and Canada. Mineralogy and Petrology, 112: 755-765.

Morteani, G., Möller, P., Dulski, P., Preinfalk, C., 2014. Major, trace element and stable isotope composition of water and muds precipitated from the hot springs of Bolivia: Are the waters of the spring's potential ore forming fluids? Geochemistry, 74(1): 49-62.

Munoz-Saez, C., Manga, M., Hurwitz, S., 2018. Hydrothermal discharge from the El Tatio basin, Atacama, Chile. Journal of Volcanology and Geothermal Research, 361: 25-35.

Munoz-Saez, C., Namiki, A., Manga, M., 2015. Geyser eruption intervals and interactions: Examples from El Tatio, Atacama, Chile. Journal of Geophysical Research: Solid Earth, 120 p 7490-7507

Munoz-Saez, C., Saltiel, S., Manga, M., Nguyen, C., Gonnermann, H., 2016. Physical and hydraulic properties of modern sinter deposits: El Tatio, Atacama. Journal of Volcanology and Geothermal Research, 325: 156-168.

Myers, K.D., 2015. The microbial ecology and biogeochemistry of cyanobacteria in the arsenic-rich and inorganic carbon-limited geothermal waters of El Tatio Geyser Field, Chile. The University of Texas at Austin.

Nicolau, C., Reich, M., Lynne, B., 2014. Physico-chemical and environmental controls on siliceous sinter formation at the high-altitude El Tatio geothermal field, Chile. Journal of Volcanology and Geothermal Research, 282: 60-76.

Peacock, C.L., Sherman, D.M., 2005. Surface complexation model for multisite adsorption of copper(II) onto kaolinite. Geochimica et Cosmochimica Acta, 69(15): 3733-3745. 
Phoenix, V.R., Bennett, P.C., Engel, A., Tyler, S., Ferris, F., 2006. Chilean high-altitude hot-spring sinters: a model system for UV screening mechanisms by early Precambrian cyanobacteria. Geobiology, 4(1): 15-28.

Plenge, M.F., Engel, A.S., Omelon, C.R., Bennett, P.C., 2017. Thermophilic archaeal diversity and methanogenesis from El Tatio geyser field, Chile. Geomicrobiology Journal, 34(3): 220-230.

Rietveld, H.M., 1969. A profile refinement method for nuclear and magnetic structures. Journal of Applied Crystallography, 2: 65-71.

Robertson, I.D., Eggleton, R.A., 1991. Weathering of granitic muscovite to kaolinite and halloysite and of plagioclase-derived kaolinite to halloysite. Clays and Clay Minerals, 39(2): 113-126.

Rodgers, K., Greatrex, R., Hyland, M., Simmons, S., Browne, P., 2002. A modern, evaporitic occurrence of teruggite, Ca 4 MgB 12 As $2 \mathrm{O}$ 28. 18H 2 O, and nobleite, CaB 6 O 10. 4H 2 O, from the El Tatio geothermal field, Antofagasta Province, Chile. Mineralogical Magazine, 66(2): 253-259.

Romero, L. et al., 2003. Arsenic enrichment in waters and sediments of the Rio Loa (Second Region, Chile). Applied Geochemistry, 18(9): 1399-1416.

Sahai, N., Sverjensky, D.A., 1997. Solvation and electrostatic model for specific electrolyte adsorption. Geochimica et Cosmochimica Acta, 61(14): 2827-2848.

Sanchez-Garcia, L. et al., 2019. Microbial Biomarker Transition in High-Altitude Sinter Mounds From El Tatio (Chile) Through Different Stages of Hydrothermal Activity. Frontiers in Microbiology, 9(3350).

Scarlett, N.V.Y., Madsen, I.C., 2006. Quantification of phases with partial or no known crystal structures. Powder Diffraction, 21(4): 278-284.

Schlegel, M.L., Descostes, M., 2009. Uranium Uptake by Hectorite and Montmorillonite: A Solution Chemistry and Polarized EXAFS Study. Environmental Science \& Technology, 43(22): 8593-8598.

Scott, A., Smith, S., 1966. Susceptibility of interlayer potassium in micas to exchange with sodium, Clays and Clay Minerals. Elsevier, pp. 69-81.

Smith, A.H. et al., 2012. Mortality in young adults following in utero and childhood exposure to arsenic in drinking water. Environmental health perspectives, 120(11): 1527-1531.

Sposito, G. et al., 1999. Surface geochemistry of the clay minerals. Proceedings of the National Academy of Sciences, 96(7): 3358-3364.

Sverjensky, D.A., Sahai, N., 1996. Theoretical prediction of single-site surface-protonation equilibrium constants for oxides and silicates in water. Geochimica et Cosmochimica Acta, 60(20): 37733797.

Tapia, J. et al., 2018. Sources, enrichment, and redistribution of $\mathrm{As}, \mathrm{Cd}, \mathrm{Cu}, \mathrm{Li}, \mathrm{Mo}$, and $\mathrm{Sb}$ in the Northern Atacama Region, Chile: Implications for arid watersheds affected by mining. Journal of Geochemical Exploration, 185: 33-51.

Tassi, F. et al., 2010. Fluid geochemistry of hydrothermal systems in the Arica-Parinacota, Tarapacá and Antofagasta regions (northern Chile). Journal of Volcanology and Geothermal Research, 192(1-2): 1-15.

Tassi, F. et al., 2009. The magmatic-and hydrothermal-dominated fumarolic system at the Active Crater of Lascar volcano, northern Chile. Bulletin of Volcanology, 71(2): 171-183.

Tournassat, C., Davis, J.A., Chiaberge, C., Grangeon, S., Bourg, I.C., 2016. Modeling the Acid-Base Properties of Montmorillonite Edge Surfaces. Environmental Science \& Technology, 50(24): 13436-13445.

Tournassat, C., Greneche, J.-M., Tisserand, D., Charlet, L., 2004. The titration of clay minerals: I. Discontinuous backtitration technique combined with CEC measurements. Journal of Colloid and Interface Science, 273(1): 224-233. 
Trindade, M.J., Dias, M.I., Coroado, J., Rocha, F., 2010. Firing tests on clay-rich raw materials from the Algarve basin (southern Portugal): study of mineral transformations with temperature. Clays and clay minerals, 58(2): 188-204.

Turvey, C.C., Hamilton, J.L., Wilson, S.A., 2018. Comparison of Rietveld-compatible structureless fitting analysis methods for accurate quantification of carbon dioxide fixation in ultramafic mine tailings. American Mineralogist, 103(10): 1649-1662.

Wilmeth, D.T. et al., 2020. Depositional evolution of an extinct sinter mound from source to outflow, El Tatio, Chile. Sedimentary Geology, 406: 105726.

Wilson, S.A., Raudsepp, M., Dipple, G.M., 2006. Verifying and quantifying carbon fixation in minerals from serpentine-rich mine tailings using the Rietveld method with X-ray powder diffraction data. American Mineralogist, 91(8-9): 1331-1341. 
A
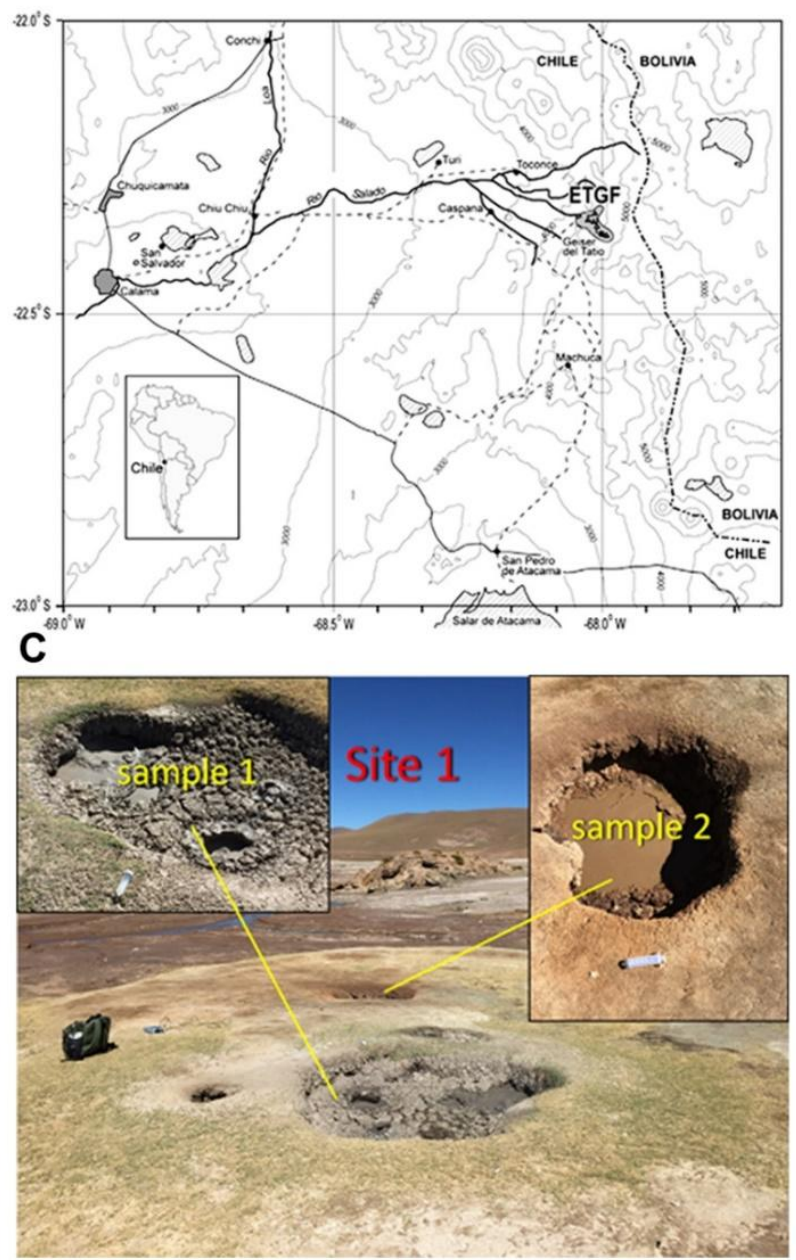

B

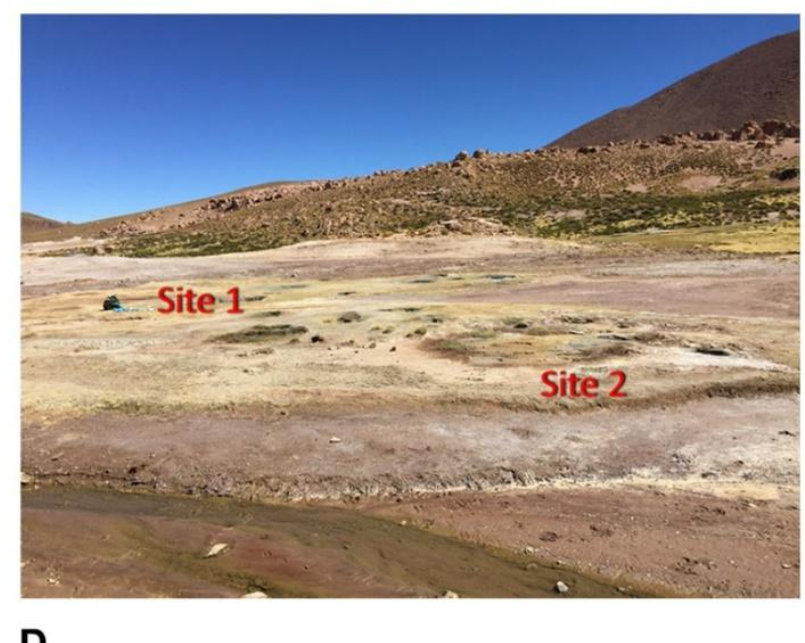

D

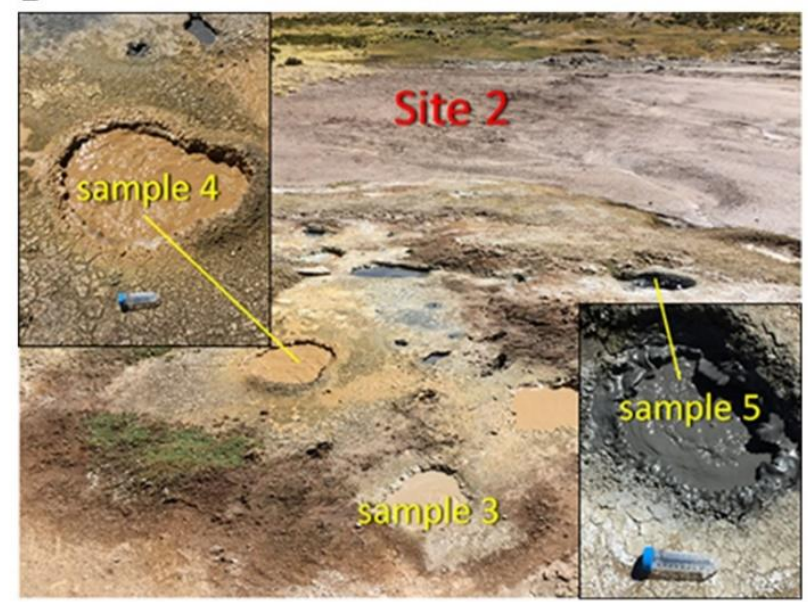

Figure 1. Map of field location with sampling sites (map modified from Landrum et al., 2009). (A) The El Tatio Geyser Field (ETGF). (B) Sampling sites of the five mud samples in the ETGF Upper basin (coordinates: $22^{\circ} 19^{\prime} 40.41^{\prime \prime} \mathrm{S}, 68^{\circ} 0^{\prime} 23.81^{\prime \prime} \mathrm{W}$ ). (C) Site 1 where sample 1 and sample 2 were collected. Backpack for scale is roughly $60 \mathrm{~cm}$ tall. (D) Site 2 where sample 3, 4, 5 were collected, standard $50 \mathrm{~mL}$ centrifuge tube $(11.5 \mathrm{~cm}$ in length and $3.2 \mathrm{~cm}$ in width) for scale. 

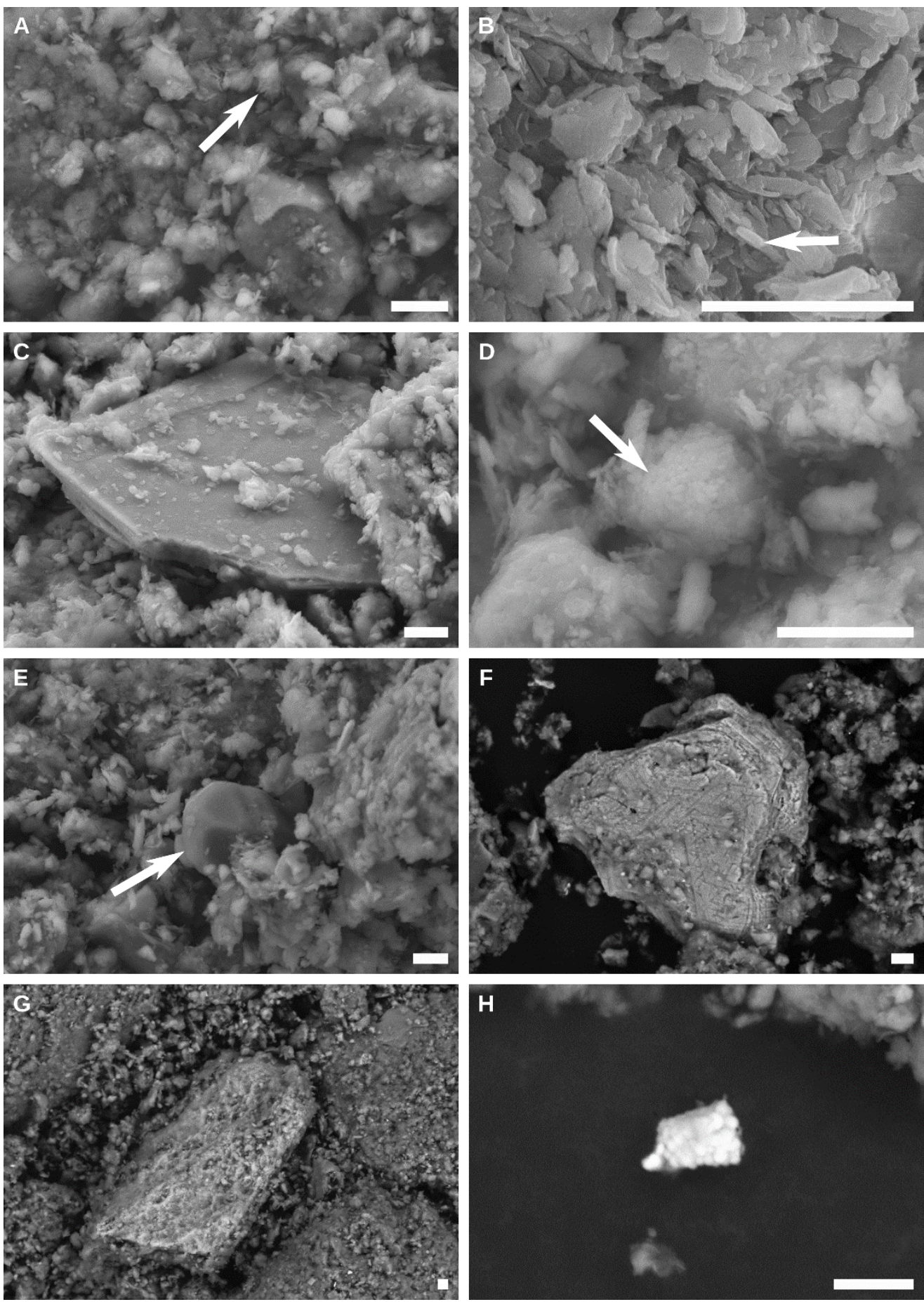

Figure 2. Scanning electron microscopy images of ETGF mud samples. (A, B) Clay aggregates from sample 1 form the majority of the sample matrix and have 50-100 nm diameter flakes on their surface, marked by arrows. (C) A large, subhedral grain of a phyllosilicate mineral from sample 2. (D, E) Sub-spherical $\mathrm{SiO}_{2}$-rich nodules (marked by arrows) from sample 1 and 2, respectively. The grain in panel $\mathrm{D}$ is possibly opal, whereas panel $\mathrm{E}$ likely depicts a detrital quartz grain. (F) Back-scattered electron image of a Fe-Ti oxide grain in sample 3. (G) Backscattered electron image of a Fe-S-As phase from sample 5. (H) Back-scattered electron image of 
an As-Sb rich particle in sample 2. The white scale bars on the bottom right corners represent 2 $\mu \mathrm{m}$.
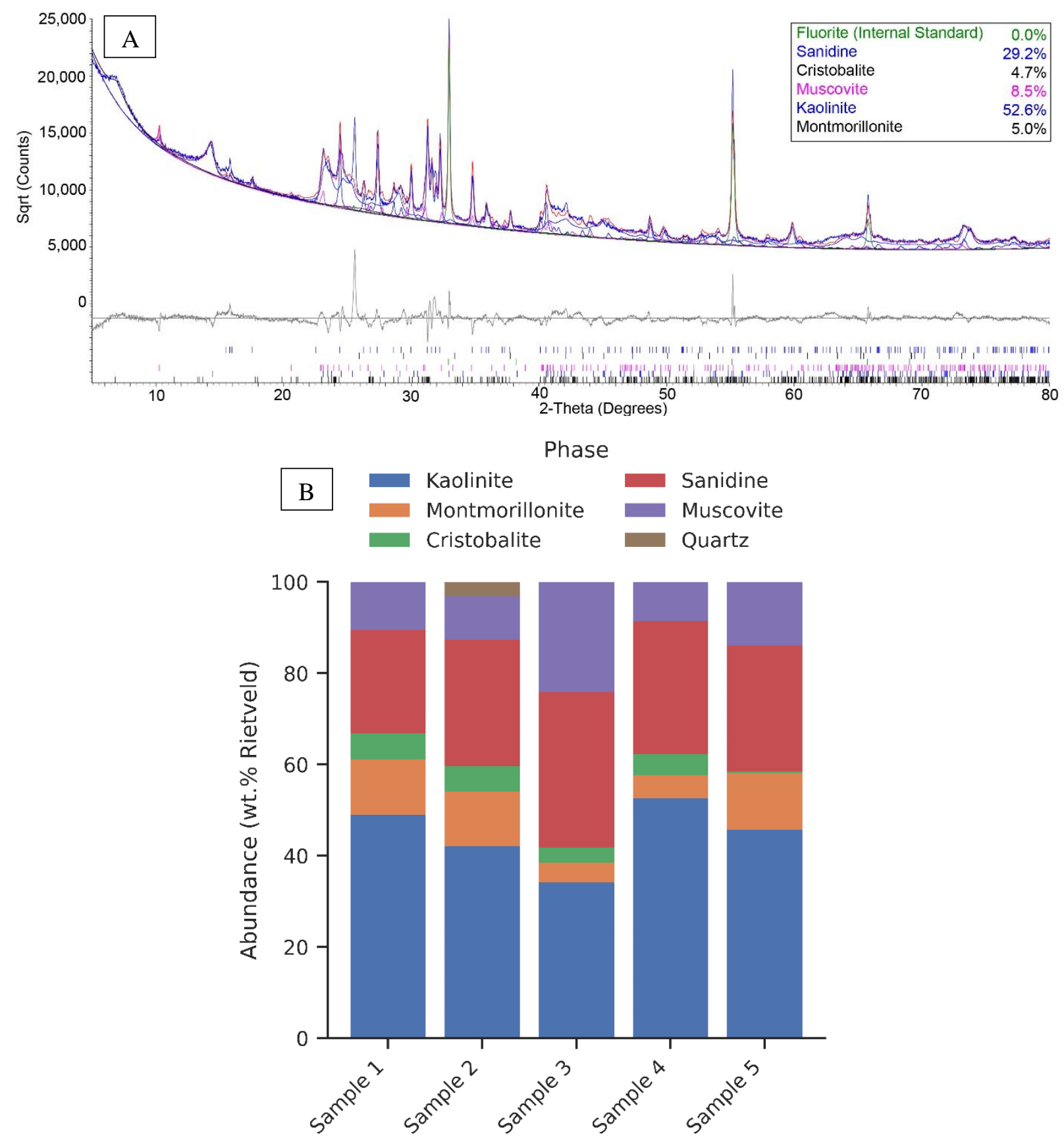

Figure 3. (A) Rietveld refinement plot for ETGF mud sample 4. Refined mineral abundances are given as wt.\% values. (B) Refined mineral abundances (wt.\%) for the five mud samples. 

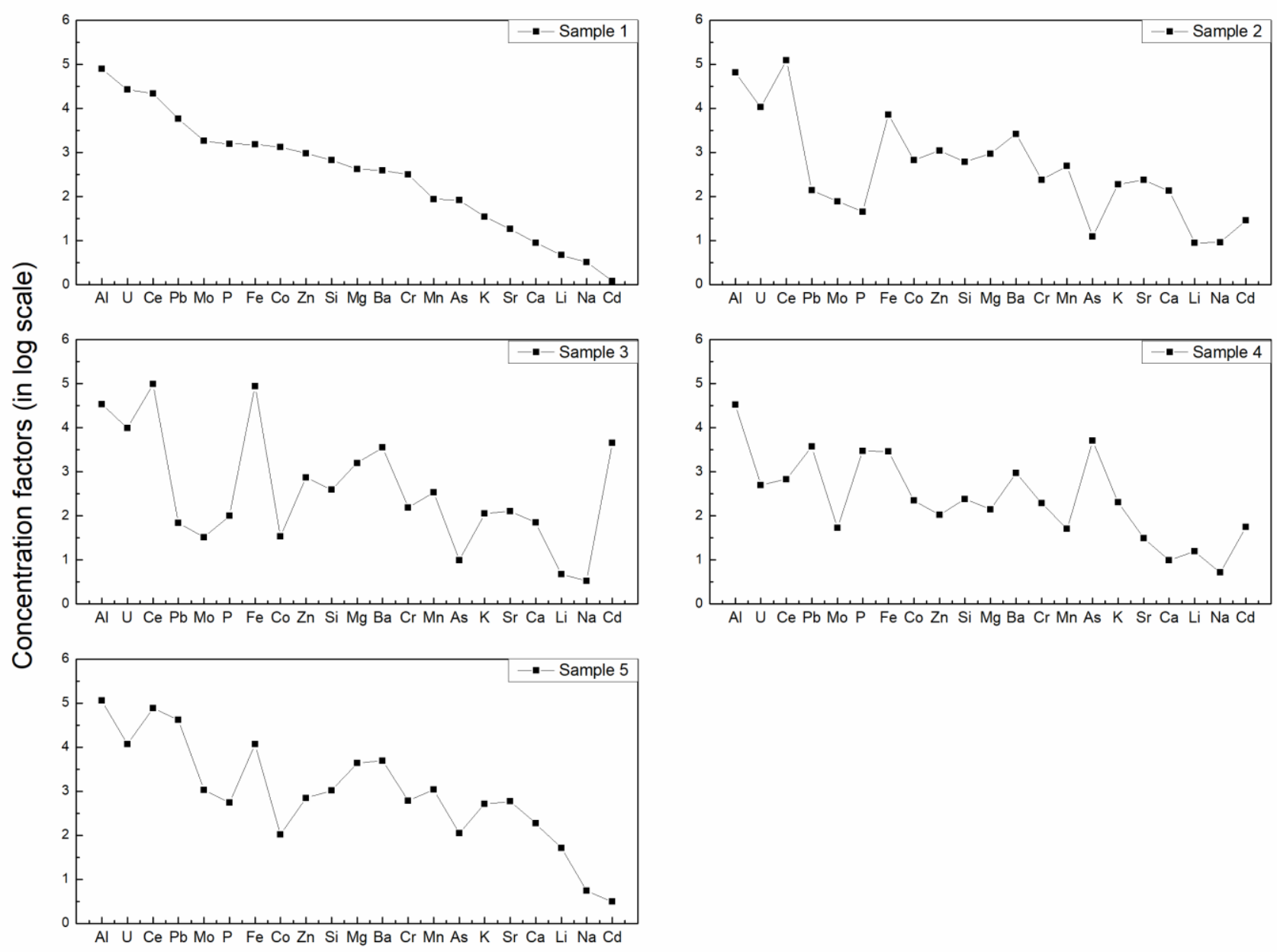

Figure 4. Relative distribution of elements between the clay and water phases (higher values mean the element is more closely bound to the solid phase). The order of elements in the $\mathrm{x}$-axis was based on the decreasing trend in Sample 1. 

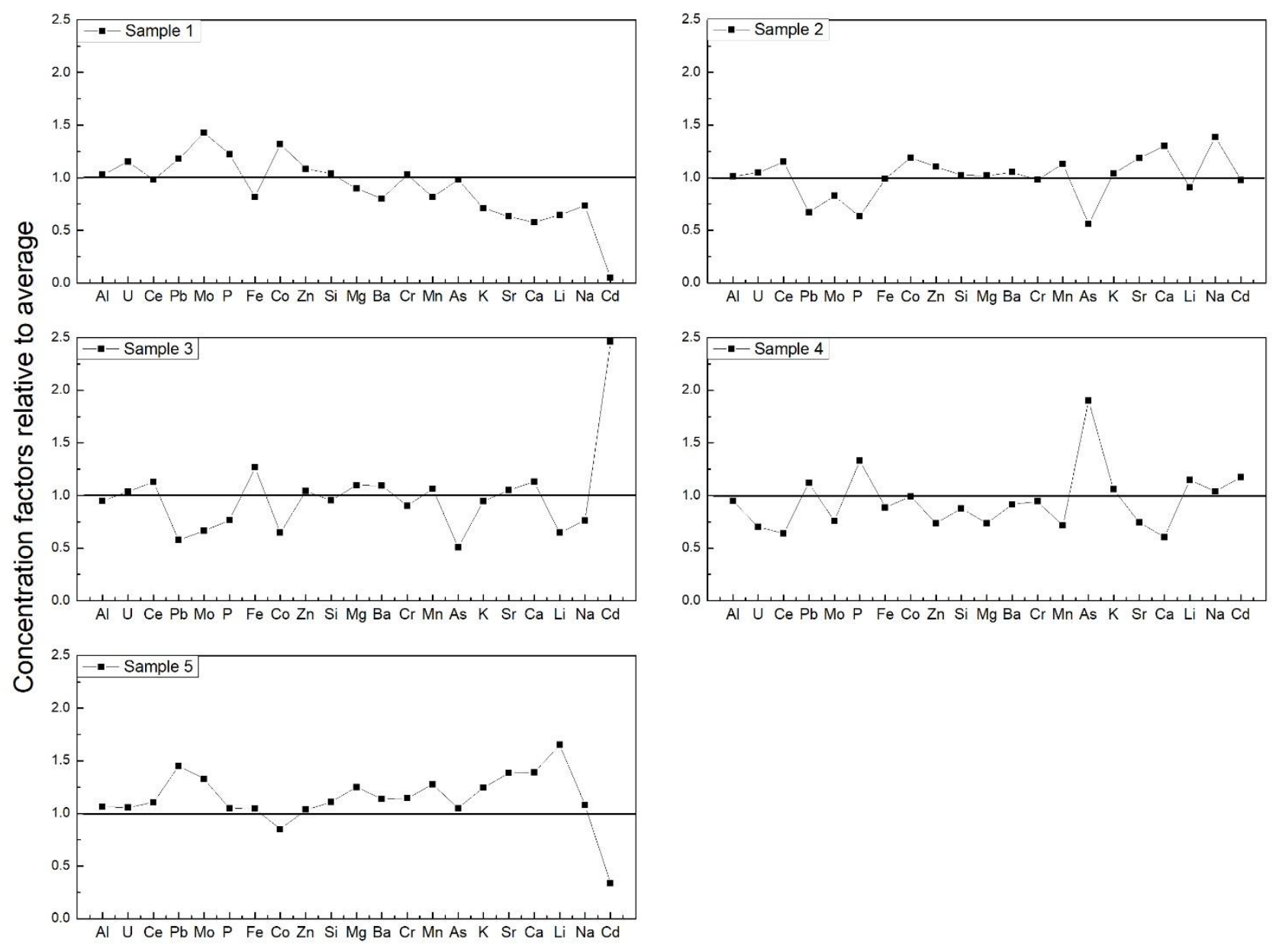

Figure 5. Concentration factors of each element relative to the average concentration factor of the element. 


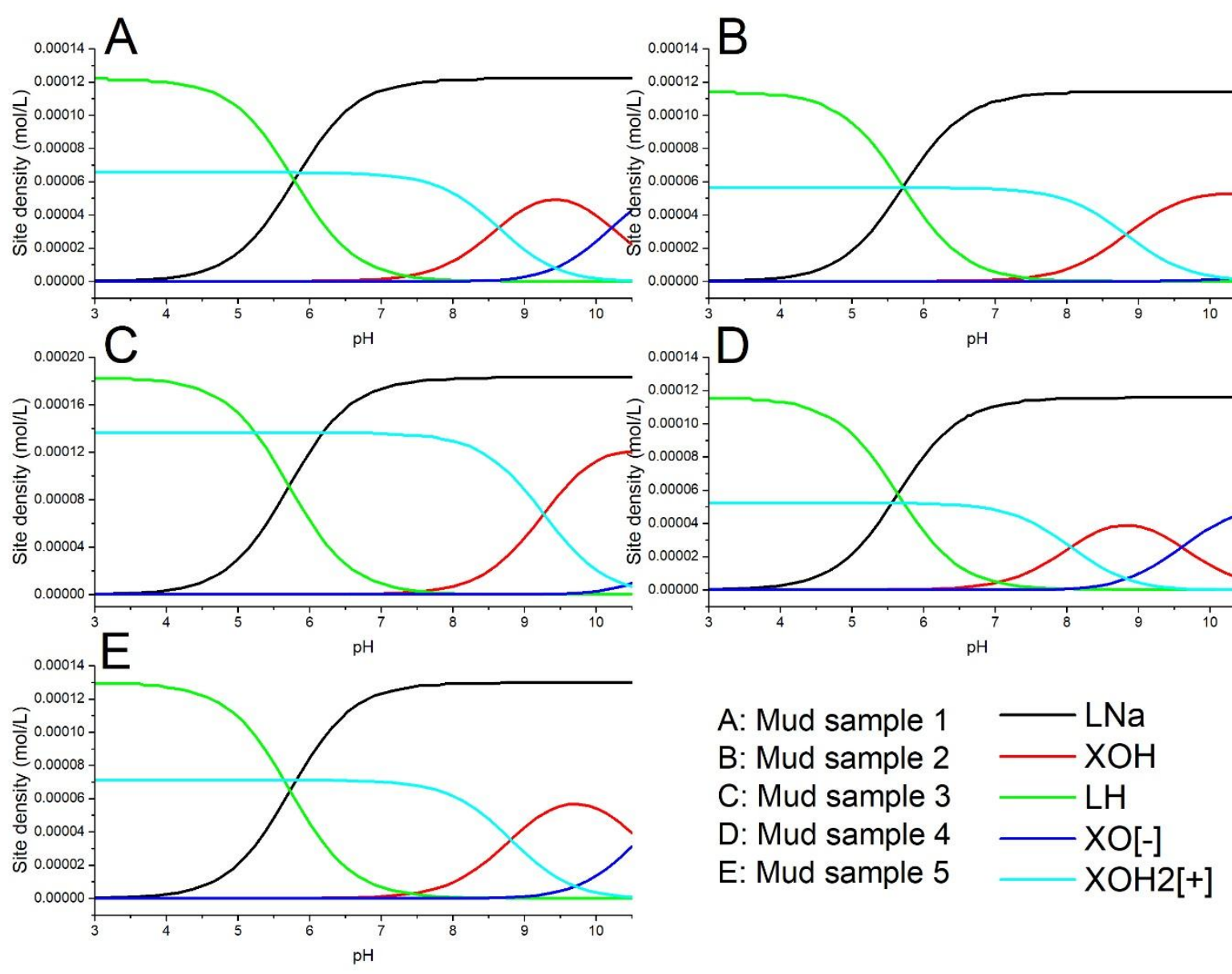

Figure 6. Surface functional group speciation diagrams for the five mud samples. The $\equiv \mathrm{LNa}$ group represents a surface group generated by isomorphic substitution and occupied by $\mathrm{Na}^{+}$ which has an inherently negative charge. The $\equiv \mathrm{LH}$ group is the protonated state of $\equiv \mathrm{LNa} ; \equiv \mathrm{XOH}$ represents amphoteric $\equiv \mathrm{Al}-\mathrm{OH}$ and $\equiv \mathrm{Si}-\mathrm{OH}$ groups; $\equiv \mathrm{XO}^{-}$and $\equiv \mathrm{XOH}_{2}{ }^{+}$are the deprotonated and protonated states of $\equiv \mathrm{XOH}$, respectively. 
Table 1. El Tatio sampling site temperatures and $\mathrm{pH}$ (sample site coordinates: $22^{\circ} 19^{\prime} 40.41^{\prime \prime} \mathrm{S}$, $\left.68^{\circ} 0^{\prime} 23.81^{\prime \prime} \mathrm{W}\right)$.

\begin{tabular}{c|cccc}
\hline & Temperature $\left({ }^{\circ} \mathrm{C}\right)$ & $\mathrm{pH}$ & $\begin{array}{c}\text { Water content of } \\
\text { mud sample (\%) }\end{array}$ & Color \\
\hline Sample 1 & 54.2 & 3.55 & 82.55 & Grey \\
Sample 2 & 40.1 & 4.87 & 82.39 & Grey to brown \\
Sample 3 & 76.2 & 5.84 & 88.87 & Brown \\
Sample 4 & 80.4 & 2.42 & 87.03 & Brown \\
Sample 5 & 76.4 & 4.01 & 75.10 & Grey \\
\hline
\end{tabular}


Table 2. Percentage of each element that is desorbed in the El Tatio mud samples during acid/base treatment.

\begin{tabular}{ccccccccccc}
\hline & \multicolumn{3}{c}{ Acid treatment $(\%)$} & \multicolumn{5}{c}{ Base treatment (\%) } \\
\hline & Sample 1 & Sample 2 & Sample 3 & Sample 4 & Sample 5 & Sample 1 & Sample 2 & Sample 3 & Sample 4 & Sample 5 \\
\hline $\mathrm{Li}$ & 85.70 & 42.49 & 50.78 & bld & bld & 68.80 & bld & 40.60 & bld & bld \\
$\mathrm{Na}$ & 100 & 42.09 & 77.72 & 100 & 97.24 & na & na & na & na & na \\
$\mathrm{Mg}$ & bld & 3.24 & 2.35 & 6.30 & 2.55 & bld & bld & bld & bld & bld \\
$\mathrm{Al}$ & bld & 3.03 & bld & bld & bld & 0.09 & 0.07 & 0.19 & 1.30 & 1.15 \\
$\mathrm{Si}$ & 0.57 & 0.73 & 0.87 & 0.61 & 0.33 & 1.30 & 0.93 & 1.46 & 2.69 & 1.41 \\
$\mathrm{~K}$ & 18.08 & 4.30 & 5.96 & bld & 2.62 & 11.63 & bld & 4.37 & bld & 1.96 \\
$\mathrm{P}$ & 7.38 & 28.64 & 33.60 & 8.80 & 35.90 & 37.50 & 31.21 & 22.85 & 31.50 & 51.06 \\
$\mathrm{Ca}$ & 61.45 & 29.20 & 46.63 & 97.19 & 64.80 & 9.62 & 3.01 & 0.82 & 11.72 & 2.43 \\
$\mathrm{Cr}$ & bld & 11.29 & bld & bld & bld & bld & bld & bld & bld & bld \\
$\mathrm{Mn}$ & 12.33 & 11.01 & 22.47 & 17.09 & 9.00 & bld & 2.18 & bld & bld & bld \\
$\mathrm{Fe}$ & 3.99 & 1.61 & 1.38 & 0.17 & 2.28 & 0.04 & 0.10 & 0.21 & 0.52 & 0.87 \\
$\mathrm{Co}$ & 19.42 & 17.02 & 9.45 & 16.88 & 100 & bld & 6.35 & 5.86 & 15.70 & 4.61 \\
$\mathrm{Zn}$ & bld & bld & bld & bld & bld & bld & 8.44 & bld & bld & 21.68 \\
$\mathrm{Sr}$ & 31.11 & 17.29 & 24.21 & 34.36 & 24.94 & 2.51 & 1.69 & bld & bld & 0.42 \\
$\mathrm{As}$ & 41.62 & 53.47 & 25.89 & 0.49 & 10.15 & 77.88 & 48.24 & 25.82 & 18.40 & 18.60 \\
$\mathrm{Mo}$ & 71.66 & 100 & 96.14 & 19.12 & 6.11 & 22.18 & 30.01 & 39.89 & 16.99 & 22.30 \\
$\mathrm{Cd}$ & 100 & 96.16 & 6.03 & bld & 38.78 & 22.79 & 38.76 & bld & bld & bld \\
$\mathrm{Ba}$ & 2.14 & 3.15 & 2.38 & 15.34 & 2.47 & bld & bld & bld & bld & bld \\
$\mathrm{Ce}$ & 0.20 & 0.15 & 0.98 & 0.70 & 0.10 & bld & 6.54 & bld & 0.89 & 0.44 \\
$\mathrm{~Pb}$ & 4.28 & 4.29 & 5.58 & 3.21 & 7.95 & 1.28 & 1.27 & 1.45 & 2.02 & 1.72 \\
$\mathrm{U}$ & 2.16 & 5.74 & 4.14 & 4.61 & 4.37 & bld & 0.37 & 4.55 & 2.07 & 1.19 \\
\hline
\end{tabular}

Note: bld means below detection limit; na means not applicable (because of the external addition of Na during base treatment); percentage is calculated by eq. 1 . 
Table 3. Surface complexation modelling parameters of acid-base titrations for the El Tatio mud samples.

\begin{tabular}{|c|c|c|c|c|c|}
\hline & $\log K$ & $\log \mathrm{K}_{\mathrm{a}-}$ & $\log K_{a+}$ & $\begin{array}{c}\equiv \mathrm{LH} \\
\text { site density }(\mathrm{mol} / \mathrm{g})\end{array}$ & $\begin{array}{c}\equiv \mathrm{XOH} \\
\text { site density }(\mathrm{mol} / \mathrm{g})\end{array}$ \\
\hline Sample 1 & 3.79 & -10.22 & 8.64 & $1.22 \mathrm{E}-04$ & $6.55 \mathrm{E}-05$ \\
\hline Sample 2 & 3.72 & -11.74 & 8.83 & $1.14 \mathrm{E}-04$ & 5.64E-05 \\
\hline Sample 3 & 3.72 & -11.59 & 9.27 & $1.83 \mathrm{E}-04$ & $1.36 \mathrm{E}-04$ \\
\hline Sample 4 & 3.64 & -9.60 & 8.06 & $1.16 \mathrm{E}-04$ & $5.23 \mathrm{E}-05$ \\
\hline Sample 5 & 3.73 & -10.60 & 8.81 & $1.30 \mathrm{E}-04$ & 7.12E-05 \\
\hline
\end{tabular}

